\title{
An Investigation of Large Cross-Track Errors in North Atlantic Tropical Cyclones in the GEFS and ECMWF Ensembles
}

\author{
Nicholas M. LeOnARdo a AND Brian A. Colle ${ }^{\mathrm{a}}$ \\ ${ }^{\text {a }}$ School of Marine and Atmospheric Sciences, Stony Brook University, State University of New York, Stony Brook, New York
}

(Manuscript received 3 February 2020, in final form 11 October 2020)

\begin{abstract}
The largest medium-range $(72-120 \mathrm{~h})$ cross-track errors (CTE) of tropical cyclone (TC) forecasts from the Global Ensemble Forecast System (GEFS) over the northern Atlantic Ocean are examined for the 2008-16 seasons. The 38 unique forecasts within the upper quartile of most negative CTEs (i.e., left-of-track bias larger than $250 \mathrm{~km}$ by $72 \mathrm{~h}$ ) do not have a clear common source of steering error, although 12 of the forecasts involve the underprediction of a weak upper-level trough to the west of the TC by $36 \mathrm{~h}$. Meanwhile, at least 18 of the 36 most positive CTEs (right-of-track bias) are associated with TCs embedded in the southwest extent of a subtropical ridge, the strength of which is increasingly underpredicted during the first $24 \mathrm{~h}$ of the forecast. Excessive height falls north of the TC are driven by overpredicted divergence aloft, which corresponds to overpredicted TC outer-core convection. The convection is triggered by a $5 \%-20 \%$ overprediction of near-TC moisture and instability in the initial conditions. Weather Research and Forecasting (WRF) Model simulations are run at 36-, 12-, and 4-km grid spacing for select right-of-track cases, using the GEFS for initial and lateral boundary conditions. The 36-km WRF reproduces the same growth of errors as the GEFS because of, in part, sharing the same stability and moisture errors in the initial conditions. Changes in the convective parameterization affect how quickly these errors grow by affecting how much convection spins up. The addition of a $4-\mathrm{km}$ nest with no convective parameterization causes the errors to grow $\sim 20 \%$ faster, resulting in an even larger right-of-track error.
\end{abstract}

KEYWORDS: Tropical cyclones; Forecast verification/skill; Numerical weather prediction/forecasting; Ensembles

\section{Introduction}

\section{a. Background}

While medium-range (day 3-5) track forecasts for North Atlantic Ocean tropical cyclones (TCs) have improved during the last three decades (Rappaport et al. 2009; Cangialosi 2018), numerical models occasionally struggle forecasting certain TCs (Carr and Elsberry 2000; Landsea and Cangialosi 2018; Torn et al. 2018), such as Hurricane Joaquin (2015). Large along-track errors can impact the timing of landfall, while large cross-track errors (CTE) can determine if or where the TC makes landfall. Understanding the commonalities of these track error events can help forecasters recognize situations when the model track guidance may be significantly biased.

Few studies have analyzed more than ten large track error TCs (Carr and Elsberry 2000; Kehoe et al. 2007; Peng et al. 2017). The methodology and diagnostics applied in individual case studies can vary, limiting how much their results can be generalized. Leonardo and Colle (2020) thus verified the European Centre for Medium-Range Weather Forecasts (ECMWF) ensemble track forecasts for the 2008-16 North Atlantic seasons and identified many cases with large along-track errors $(>500 \mathrm{~km})$ in the medium range. The 27 largest negative along-track (slow) biases involved recurving TCs that underwent extratropical transition (ET) upon interacting with upstream 300-hPa trough-ridge

Corresponding author: Brian A. Colle, brian.colle@stonybrook.edu couplet at midlatitudes. The trough-ridge couplets were underamplified, largely because of weak biases in $300-200-\mathrm{hPa}$ potential vorticity advection by the TC's divergent outflow. The underpredicted outflow was attributed to prior errors in near-TC precipitation and $700-\mathrm{hPa}$ moisture fluxes around the TC.

Track forecasts south of $30^{\circ} \mathrm{N}$ are often degraded for reasons not involving extratropical transition (non-ET cases). Aberson (2008) analyzed several Global Forecast System (GFS) forecasts over the North Atlantic in 2004 and 2005 and found that large northward track biases of TCs like Frances (2004) and Ophelia (2005) were from erroneous positive vorticity anomalies north of the TC, which merged with and weakened the outer edge of the subtropical ridge. Aberson (2008) noted that the initial near-TC errors grew rapidly during the first $24 \mathrm{~h}$ and were likely introduced by either inadequate quality control of faulty synoptic surveillance dropsonde observations or issues with the GFS's data assimilation method.

Weather Research and Forecasting (WRF) Model (Skamarock et al. 2008) simulations have been run to examine specific cases of TC track error. Wang et al. (2017) investigated the erroneous northward turn of Typhoon Megi (2010), which was due to an underprediction of the western Pacific subtropical high. Initializing the model with either larger or stronger TCs resulted in larger low-level mass fluxes from the high to the TC, which weakened the high faster and allowed for more erroneous northward tracks.

Galarneau and Davis (2013) ran WRF simulations for 27 North Atlantic TCs from 2008 to 2010. Earl (2010) and Fiona 
(2010) had large steering errors due to an underprediction of a steering 700-600-hPa subtropical ridge to the north of the TC center. It was suggested that the underpredicted ridge was due to insufficient low-level heating caused by a lack of proper aerosol treatment in the WRF Model. Torn and Davis (2012) ran WRF for four North Atlantic TCs in 2008 and noted a westward track bias caused by overpredicted $700-\mathrm{hPa}$ easterlies north of the Caribbean Sea islands. The overpredicted easterlies corresponded to a positive middle-tropospheric temperature bias caused by insufficient vertical mixing of heat from the Kain-Fritsch (Kain and Fritsch 1990) convective scheme. Switching to the Tiedke (Zhang et al. 2011) convective scheme ameliorated the easterly wind bias, though there was a westerly wind bias between $10^{\circ}$ and $20^{\circ} \mathrm{N}$.

\section{b. Motivation}

Many studies have analyzed large error cases in the tropics; however, the details about these errors have varied between the studies over time, and only a limited number of cases were analyzed. This paper extends the work of Leonardo and Colle (2020) by examining many non-ET cases with large 72-120-h cross-track biases during the 2008-16 period. The Global Ensemble Forecast System (GEFS) is also assessed in detail as it was shown to have the largest mean right-of-track biases of the models verified by Leonardo and Colle (2017). The experiments are designed to help answer the following three main scientific questions:

1) Do the locations and intensities of large right-of-track cases differ from large left-of-track cases?

2) What are the synoptic features or mechanisms associated with large right-of-track cases and do they differ from large left-of-track cases?

3) Can the model errors in the right-of-track cases be traced back to the initial conditions and is the error growth sensitive to differences in the model's treatment of convection?

The data and method are described in section 2 . The results are discussed in section 3 , and section 4 provides the summary and conclusions.

\section{Data and methods}

\section{a. Track data and definition of large error events}

This study uses the same validation dataset and general approaches as for the along-track errors of ET events in Leonardo and Colle (2020), including the definitions of ET events and along- and cross-track errors. For this study, each forecast must have at least eight GEFS ensemble members and eight ECMWF ensemble members with tracker data by $72 \mathrm{~h}$, which results in enough members and cases to obtain statistical significance (e.g., Buckingham et al. 2010; Leonardo and Colle 2017). These requirements result in the same 357 nontransitioning (non-ET) forecasts shown in Fig. 1 of Leonardo and Colle (2020). The GEFS forecasts for these non-ET cases are the focus of this study given that they

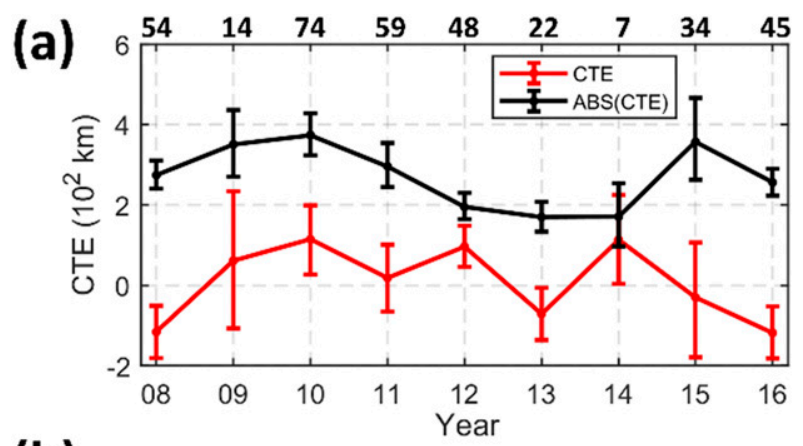

(b)

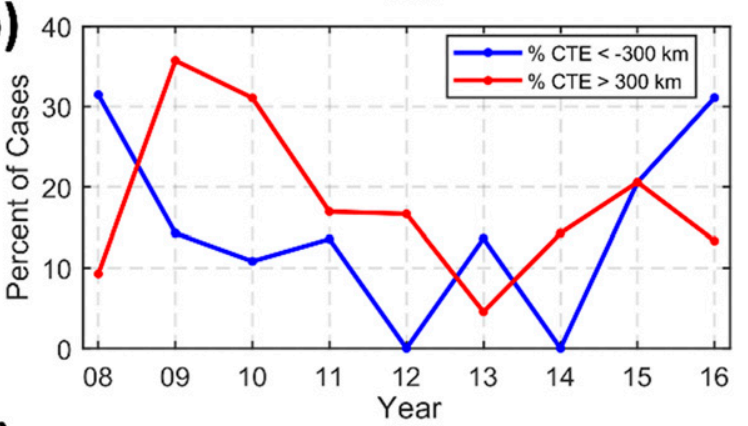

(c)

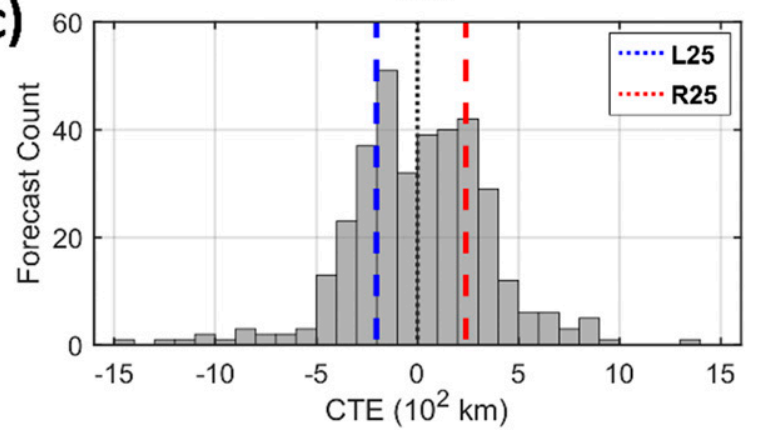

FIG. 1. (a) Annual average CTEs (red) and absolute CTEs (black) of the GEFS mean 72-120-h forecasts for non-ET cases, with the number of forecasts annotated above. The bars are the $95 \%$ confidence interval of the sample mean calculated by bootstrap resampling. (b) Annual percentage of GEFS mean 72-120-h forecasts for cases with CTEs greater than $300 \mathrm{~km}$ left of track (blue) and right of track (red). (c) A histogram of the largest 72-120-h GEFS mean CTEs, with blue and red lines showing the thresholds for the L25 and R25 cases.

are less dominated by large along-track errors (ATE). The GEFS TC track and intensity forecasts are verified against the NHC best-track data, all of which are archived by NHC (ftp://ftp.nhc.noaa.gov/atcf/archive/). The ECMWF tracks are archived by the THORPEX Interactive Grand Global Ensemble (TIGGE; Bougeault et al. 2010) database and are available online (at http://rda.ucar.edu/datasets/ds330.3/).

In focusing on GEFS mean 72-120-h CTEs of non-ET cases, it is seen that the annual averages switch between positive and negative several times throughout the 200816 period, although the average magnitude of CTEs decreases by $\sim 200 \mathrm{~km}$ between 2010 and 2013 (Fig. 1a). The confidence intervals in this and other plots (unless stated otherwise) are the $95 \%$ confidence intervals calculated via 
TABLE 1. List of L25 cases by storm name (forecast cycle).

\begin{tabular}{lcc}
\hline & L25-case TCs (forecast cycles) analyzed & \\
\hline Bertha (0000 UTC 5 Jul 2008) & Irene (0000 UTC 21 Aug 2011) & Ida (1200 UTC 20 Sep 2015) \\
Dolly (0000 UTC 22 Jul 2008) & Lee (0000 UTC 10 Sep 2011) & Joaquin (1200 UTC 28 Sep 2015) \\
Fay (0000 UTC 16 Aug 2008; & Nate (0000 UTC 23 Sep 2011; & Gaston (1200 UTC 24 Aug 2016; \\
1200 UTC 19 Aug 2008) & 1200 UTC 25 Sep 2011) & UTC 27 Aug 2016) \\
Gustav (0000 UTC 26 Aug 2008) & Ophelia (1200 UTC 28 Sep 2011; & Karl (0000 UTC 15 Sep 2016; \\
& 1200 UTC 3 Sep 2011) & 1200 UTC 18 Sep 2016) \\
Hanna (1200 UTC 29 Aug 2008) & Ophelia (1200 UTC 25 Sep 2011; & Lisa (0000 UTC 21 Sep 2016) \\
& 1200 UTC 1 Oct 2011) & Mathew (0000 UTC 30 Sep 2016) \\
Ike (0000 UTC 9 Sep 2008) & Helene (1200 UTC 11 Aug 2012) & Nicole (0000 UTC 5 Oct 2016) \\
Josephine (0000 UTC 3 Sep 2008) & Leslie (1200 UTC 4 Sep 2012) & \\
Paloma (1200 UTC 6 Nov 2008) & Nadine (1200 UTC 25 Sep 2012) & \\
Fred (0000 UTC 9 Sep 2009; & Dorian (0000 UTC 26 Jul 2013) & \\
1200 UTC 11 Sep 2009) & & \\
Colin (1200 UTC 3 Aug 2010) & Erin (0000 UTC 15 Aug 2013) & \\
Gaston (1200 UTC 3 Sep 2010) & Gabrielle (0000 UTC 7 Sep 2013) & \\
Lisa (1200 UTC 21 Sep 2010) & Humberto (1200 UTC 12 Sep 2013) & \\
Tomas (1200 UTC 4 Nov 2010) & Ingrid (0000 UTC 14 Sep 2013) & \\
\hline
\end{tabular}

bootstrap resampling, in which the dataset is randomly resampled 1000 times with replacement (Zwiers 1990). During the 2009-13 period, the percentage of CTEs more than $300 \mathrm{~km}$ right of track decreases from $35 \%$ to $5 \%$, while the percentage of CTEs more than $300 \mathrm{~km}$ left of track varies each year (Fig. 1b). However, the large variability in both the total number of forecasts per year and the average CTEs outside the 2009-13 period makes it difficult to determine whether there is a trend consistent with model upgrades.

Anomalous CTEs are defined with respect to the GEFS climatological CTEs for the 2008-16 period, similar to Leonardo and Colle (2020). The largest GEFS ensemble mean CTE is taken between 72 and $120 \mathrm{~h}$ of each forecast of a non-ET case. The resulting distribution of CTEs is plotted in Fig. 1c. The lower (left of track) and upper (right of track) quartiles of the distribution are compiled and called "left 25\%" (L25) and "right 25\%" (R25) cases, respectively. The quartiles are chosen as a compromise between maintaining adequate sample sizes in each subset, at the expense of including cases with CTEs as small as $\sim 250 \mathrm{~km}$.

Successive GEFS forecasts for the same TCs are then removed from the L25 and R25 subsets. For each of the L25 (R25) TCs, the most negative (positive) CTE forecast is included, as well as the second most negative (positive) CTE forecast if initialized at least $48 \mathrm{~h}$ before or after the first was initialized, and so on. This minimizes the "double counting" of forecasts that are similar because one has initial conditions that have not changed much from the previous. The 48-h separation also prevents long-lived TCs, such as Ophelia (2011), from constituting a large fraction of a subset. The result is 38 L25 cases (Table 1) and 36 R25 cases (Table 2).

\section{b. Meteorological fields and compositing techniques}

The ECMWF and GEFS gridded forecast fields are archived by TIGGE and the NOAA Operational Model Archive and

TABLE 2. List of R25 cases by storm name (forecast cycle).

\begin{tabular}{lll}
\hline \hline & R25-case TCs (forecast cycles) analyzed & \\
\hline Bertha (0000 UTC 11 Jul 2008) & Emily (1200 UTC 2 Aug 2011) & Edouard (0000 UTC 12 Sep 2014) \\
Gustav (0000 UTC 29 Aug 2008) & Lee (0000 UTC 8 Sep 2011) & Erika (0000 UTC 25 Aug 2015) \\
Hanna (0000 UTC 29 Aug 2008) & Maria (0000 UTC 8 Sep 2011) & Fred (0000 UTC 1 Sep 2015) \\
Ike (1200 UTC 7 Sep 2008) & Nate (0000 UTC 22 Sep 2011) & Joaquin (0000 UTC 28 Sep 2015) \\
Bill (0000 UTC 17 Aug 2009) & Ophelia (1200 UTC 25 Sep 2011; & Mathew (1200 UTC 1 Oct 2016) \\
Fred (0000 UTC 8 Sep 2009) & 1200 UTC 1 Oct 2011) & Nicole (0000 UTC 8 Oct 2016) \\
Alex (0000 UTC 27 Jun 2010) & Philippe (0000 UTC 24 Oct 2011) & \\
Danielle (0000 UTC 23 Aug 2010) & Florence (1200 UTC 4 Aug 2012) & \\
Earl (0000 UTC 27 Aug 2010) & Helene (0000 UTC 10 Aug 2012) & \\
Igor (0000 UTC 9 Sep 2010; 1200 UTC 13 Sep 2010) & Isaac (0000 UTC 22 Aug 2012; & \\
& 1200 UTC 24 Aug 2012) & \\
Julia (0000 UTC 13 Sep 2010) & Leslie (1200 UTC 30 Aug 2012) & \\
Richard (1200 UTC 21 Oct 2010) & Michael (1200 UTC 6 Sep 2012) & \\
Tomas (1200 UTC 30 Oct 2010; 0000 UTC 3 Nov 2010) & Nadine (0000 UTC 24 Sep 2012) & \\
& Erin (0000 UTC 16 Aug 2013) & \\
\hline
\end{tabular}




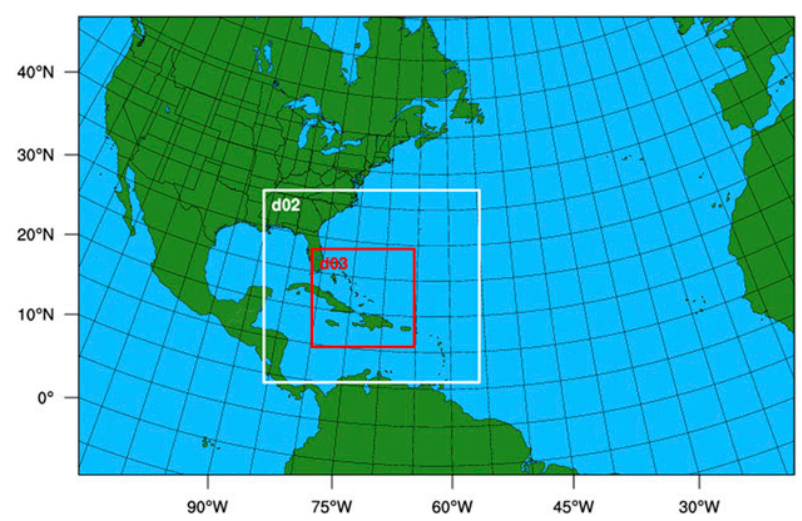

FIG. 2. Geographical locations of the WRF domains. The horizontal grid spacing on the parent domain is $36 \mathrm{~km}$ on the parent domain and is 12 and $4 \mathrm{~km}$ on the inner domains, respectively. The two inner domains are two-way moving nests centered on the TC.

Distribution System (NOMADS; https://www.ncdc.noaa. gov/data-access/model-data/model-datasets/global-ensembleforecast-system-gefs), respectively. The NOMADS archive has fields available at $1^{\circ}$ resolution and pressure levels every $50 \mathrm{hPa}$ from 1000 to $\sim 50 \mathrm{hPa}$, while TIGGE has $0.5^{\circ}$ grids for only seven mandatory pressure levels.

The deep-layer (850-200-hPa) mean environmental steering flow is calculated following Galarneau and Davis (2013). The irrotational and nondivergent winds are removed within $5^{\circ}$ of the TC center before taking a pressure-weighted average of the layer. While the 850-200-hPa layer may not be the optimal steering flow for all TCs, it provides a consistent comparison of the deep synoptic environment across the cases. While the chosen radius is larger than the $3^{\circ}-4^{\circ}$ average radius determined by Galarneau and Davis (2013), the plots of steering flow shown in this study change little when using smaller radii (not shown).

The same compositing techniques described by Leonardo and Colle (2020) are applied to gridded meteorological fields in this study. The best-track-relative composites center each of the ensemble member grids on the best-track latitude/longitude position, whereas the TC-relative composites center the ensemble member grids on the latitude/longitude positions of their respective TCs. The best-track-relative framework better captures the differences in the large-scale environment (e.g., synoptic systems moving independently of the TC), which may be distorted if the ensemble spread of TC positions is large. The TC-relative framework better captures differences in the TC structure and the near-TC environment. Both methods use bilinear interpolation to center the grids onto the TC position.

Different approaches were used to analyze the surrounding flow and pressure patterns associated with the CTEs, such as ensemble sensitivity (Ancell and Hakim 2007) and differences between ensemble members. Leonardo and Colle (2020) highlight the results from these approaches. This paper focuses on the standardized differences following Torn et al. (2015), in which for each case, the differences (a)

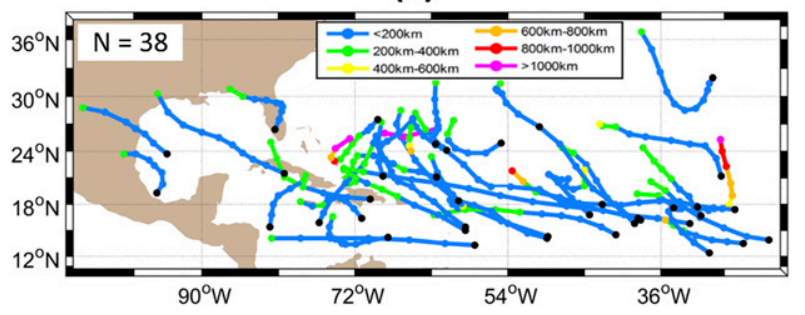

(b)

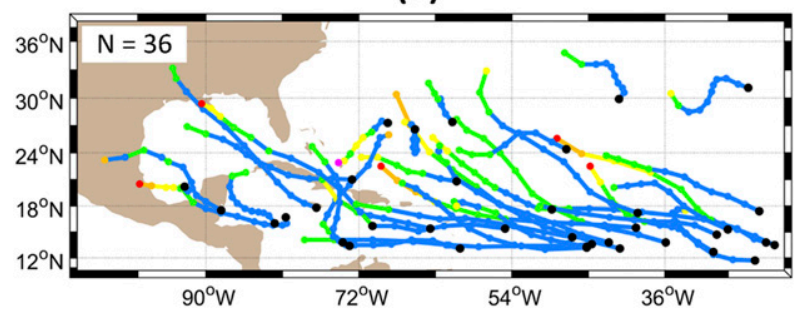

FIG. 3. Best tracks of (a) L25 and (b) R25 cases, color coded by CTE. The positions at the forecast initializations are given by the black dots. The colored dots marking the best-track position at the end of the forecast are larger.

are calculated between two sets of four members sorted by their CTEs. Specifically, at the time of largest ensemble mean track error, the member CTEs are sorted. The four most negative members are considered "leftmost", and the four most positive members are considered "rightmost." In many R25 cases, almost all ensemble members are right of the best track, such that the leftmost members have the smallest track errors. Similarly, in many L25 cases, almost all ensemble members are left of the best track, such that the rightmost members have the smallest track errors. The standardized differences between the two subgroups of an $\mathrm{R} 25$ case are calculated as follows:

$$
\Delta x_{i}=\frac{\bar{x}_{i}^{\text {rightmost }}-\bar{x}_{i}^{\text {leftmost }}}{\sigma_{x_{i}}},
$$

where $\bar{x}_{i}^{\text {rightmost }}$ and $\bar{x}_{i}^{\text {leftmost }}$ denote the mean of the $i$ th state variable for the four rightmost and leftmost ensemble members, respectively, and $\sigma_{x_{i}}$ is the ensemble standard deviation of $x_{i}$ computed from all ensemble members. To assess the statistical significance of $\Delta x_{i}$ for a single case, two subsets of four ensemble members are randomly drawn from the full ensemble 1000 times. Each time, the difference of the two means is calculated, thereby giving the $95 \%$ confidence bounds on $\Delta x_{i}$.

The GEFS forecast fields are also compared with those of the full ECMWF ensemble. The statistical significance of the difference between the GEFS and ECMWF ensemble means of meteorological fields is estimated in a similar manner to the standardized differences. For each case, the $95 \%$ confidence bounds are created by calculating the GEFS-ECMWF mean difference 1000 times, each time randomly extracting eight ensemble members from the 

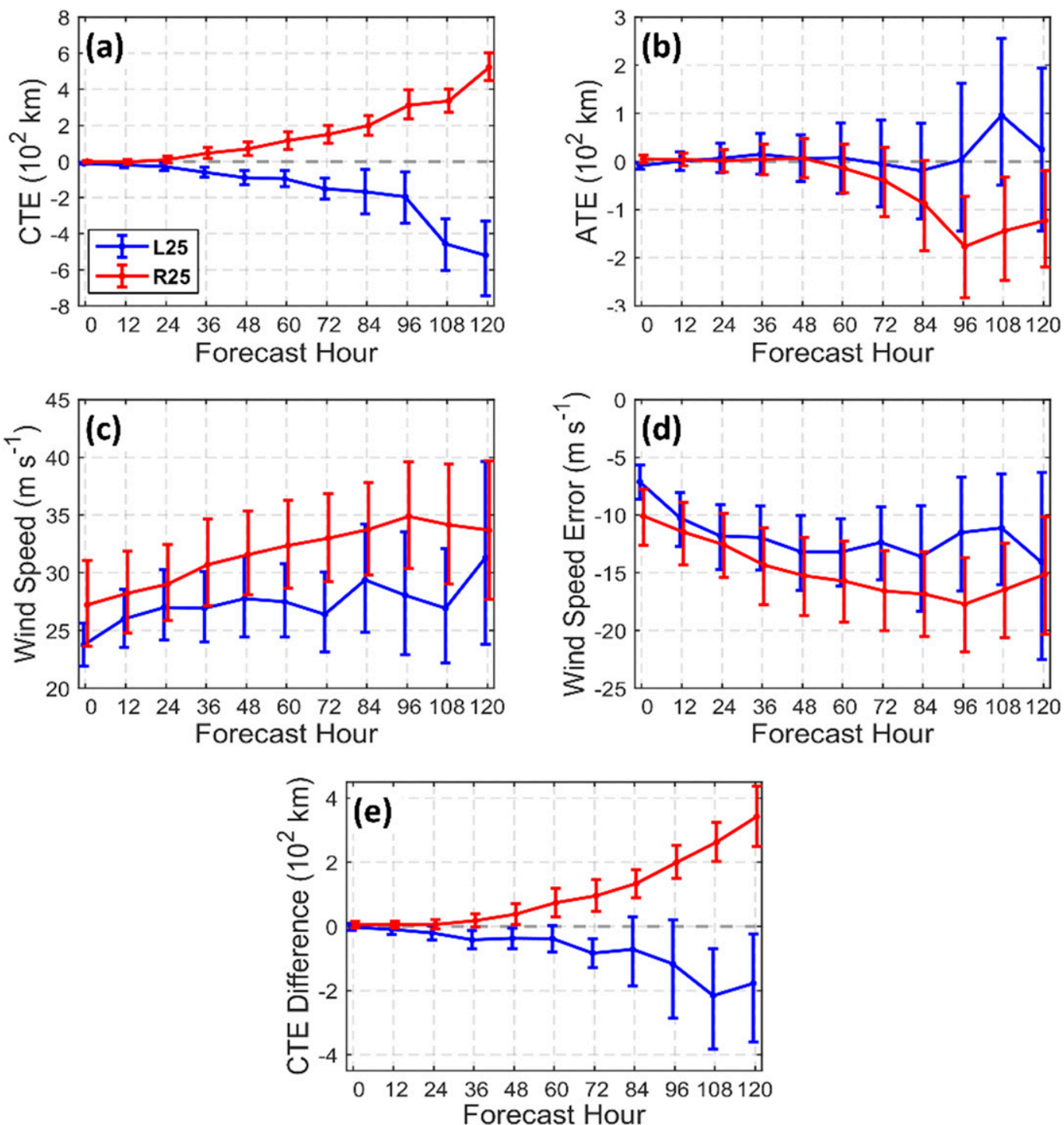

FIG. 4. GEFS ensemble mean (a) CTEs, (b) ATEs, (c) best-track TC maximum surface wind speeds, and (d) TC maximum surface wind speed errors averaged as functions of forecast hour for L25 and R25 cases. (e) GEFS-minusECMWF ensemble mean CTE differences averaged for L25 and R25 cases. The bars are the 95\% confidence interval of the sample mean.

GEFS and ECMWF with replacement. These differences are not standardized as the two sets are not drawn from the same sample (i.e., the ECMWF and GEFS have different standard deviations).

\section{c. WRF ensemble experiments}

The error growth associated with convective processes can occur on time scales shorter than the 6-hourly data available in the TIGGE data. A higher frequency of model output allows for diagnostics that involve temporal derivatives. The impact of model resolution and different convection schemes on large track error cases is also worth exploring.

The GEFS $1^{\circ}$ gridded data archived by NOMADS is used to initialize WRF ensemble forecasts for two cases with right-of-track errors to be discussed in sections $3 \mathrm{~d}$ and $3 \mathrm{e}$. More specifically, version 3.9.1 of the Advanced Research core of WRF (ARW; Skamarock et al. 2008) is used in these experiments. The $21 \mathrm{GEFS}$ members provide the initial and lateral boundary conditions.

Figure 2 shows the WRF domain setup for Ike (2008). The first set of runs for each case use only the outer $36-\mathrm{km}$ domain, which covers a large area similar in dimension to the domain used by Torn and Davis (2012) and has a similar horizontal resolution as the GEFS for the 2008-16 period. Adding inner 12- and 4-km nests tests the effects of increasing model resolution to convective-permitting levels. These inner nests are two-way interactive and follow the TC center. All nests have 36 vertical levels extending up to $20 \mathrm{hPa}$. 

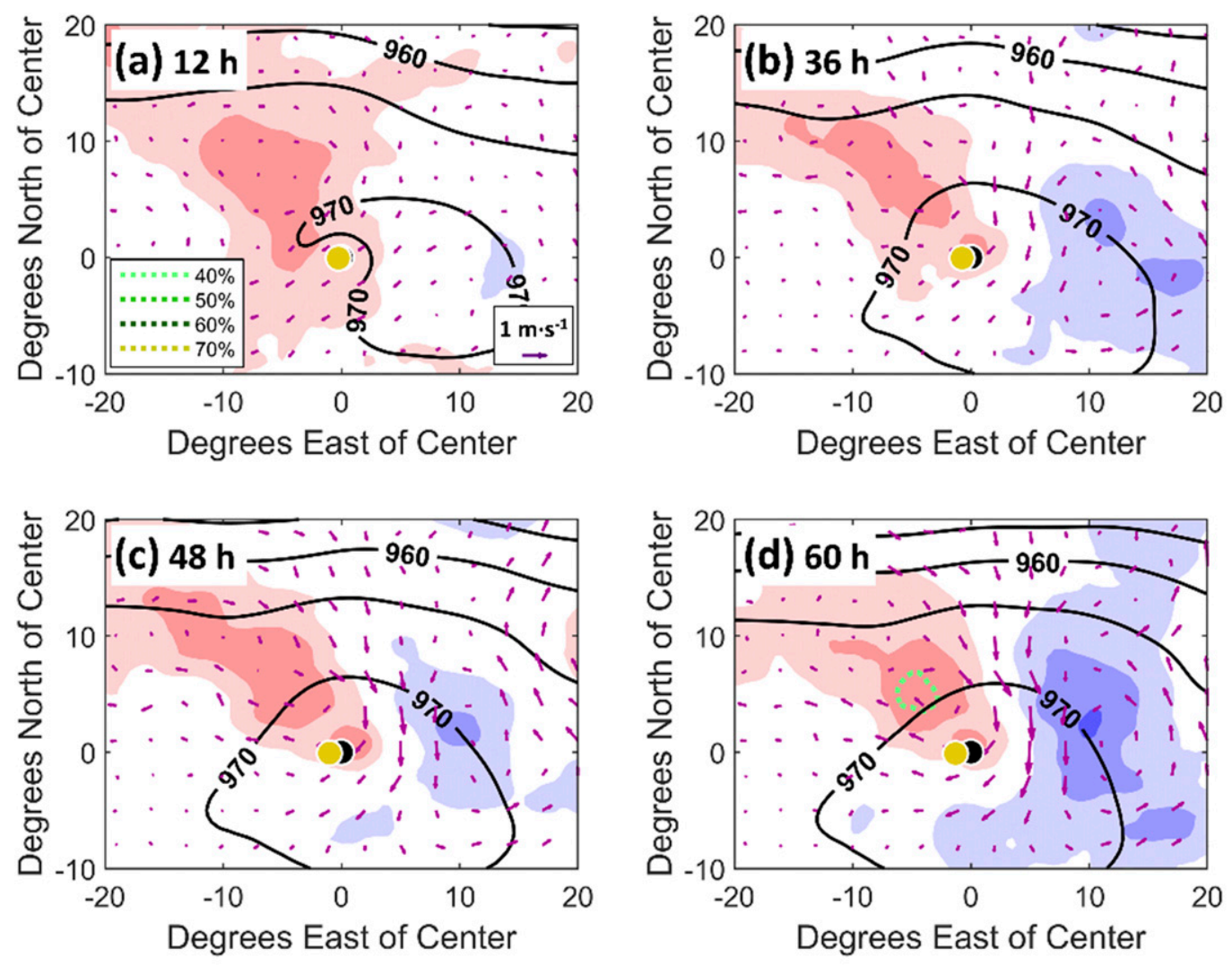

$\begin{array}{lllllllllll}-1 & -0.8 & -0.6 & -0.4 & -0.2 & 0 & 0.2 & 0.4 & 0.6 & 0.8 & 1\end{array}$

FIG. 5. Best-track-relative composites of standardized differences (four leftmost - four rightmost ensemble members) in 300-hPa geopotential height (shaded) for L25 cases at (a) 12, (b) 36, (c) 48, and (d) 60 h. Percentages of L25 cases in which the difference at each grid point is statistically significant are contoured in different shades from green to gold. Black contours are the composited 300-hPa geopotential heights (dam) of the full ensemble mean, and vectors indicate the rightmost - leftmost member differences in 850-200-hPa mean steering flow (after removing the TC circulation $5^{\circ}$ from the TC center). The black and yellow dots indicate the best-track and ensemble mean TC positions, respectively.

The 36- and 12-km nests use the simplified ArakawaSchubert (SAS) convective scheme (Pan and Wu 1995; Han and Pan 2011) to be consistent with the GEFS model. The Tiedtke convection scheme (Zhang et al. 2011), which is used in the ECMWF, is also tested for comparison. The rapid radiative transfer model for global climate models (RRTMG) is used to match the long- and shortwave radiation parameterizations in GEFS.

The GEFS's planetary boundary layer and microphysics schemes are not available in the ARW core. Instead, the WRF 6-class microphysics scheme (Hong et al. 2004), Yonsei University (YSU) boundary layer scheme (Hong et al. 2006), and the Noah land surface model (Ek et al. 2003) are used, consistent with many other studies running WRF-ARW to simulate TC track forecasts (e.g., Torn and Davis 2012; Galarneau and Davis 2013; Taraphdar et al. 2014; Melhauser et al. 2017). While the impact of microphysics on TC track may be important (Sun et al. 2015), microphysics schemes other than the WSM6, including the WSM3, did not result in significantly different track forecasts in this study. The YSU boundary layer scheme has a first-order nonlocal formulation conceptually similar to the one used by the GEFS.

\section{Results}

\section{a. Climatology of TCs with large cross-track errors}

Verification statistics of the L25 and R25 cases are first compared to assess whether the two sets have inherent differences in their tracks or intensities. Figure 3 shows the verifying best tracks for the L25 and R25 GEFS cases. The spatial distribution of the two sets is similar, albeit more R25 cases involve TCs steered by persistent easterlies over the main development region south of $20^{\circ} \mathrm{N}$. Thus, it is not obvious from the best-track positions that the L25 and R 25 cases involve inherently different TC environments and life cycles. 

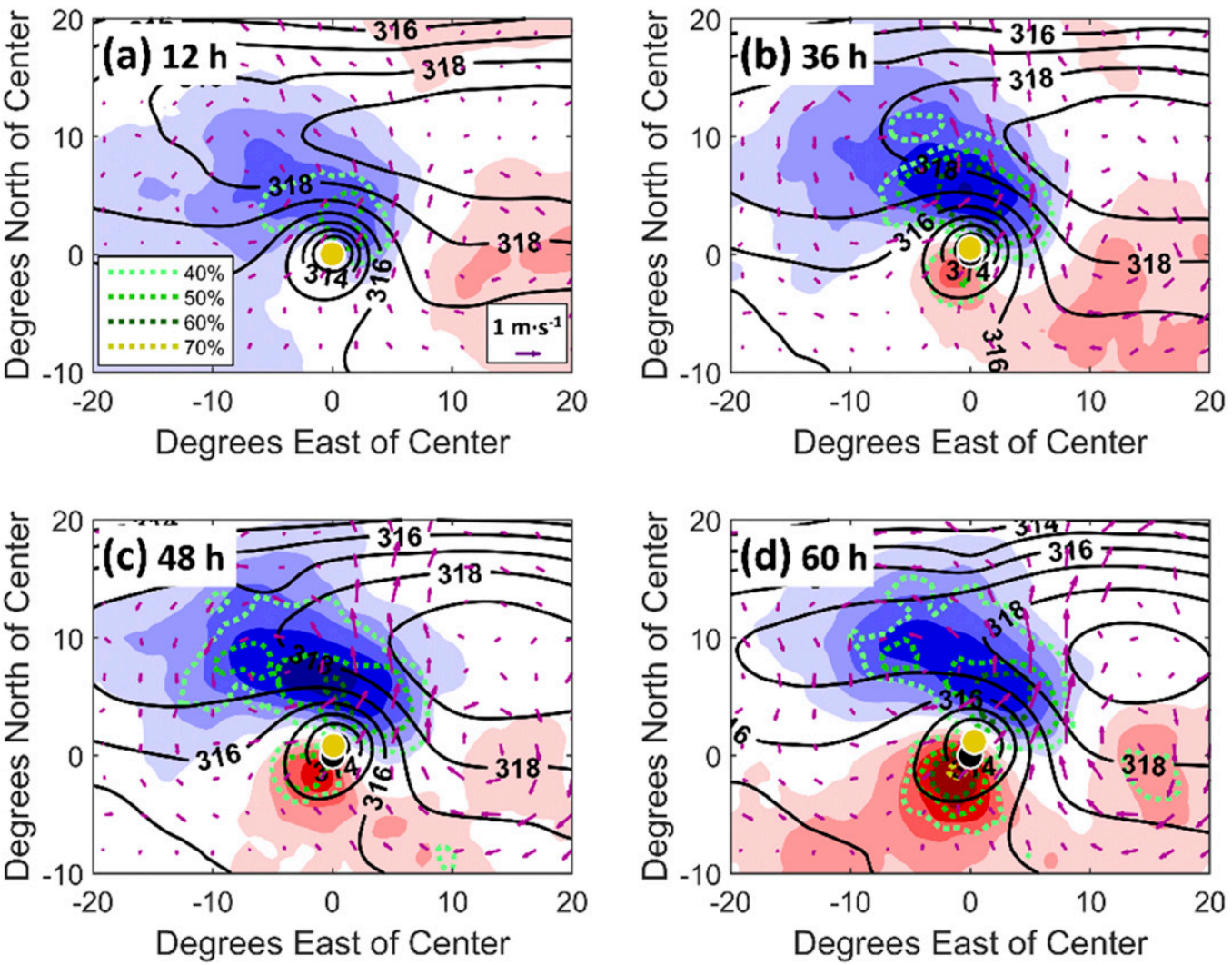

$\begin{array}{lllllllllll}-1 & -0.8 & -0.6 & -0.4 & -0.2 & 0 & 0.2 & 0.4 & 0.6 & 0.8 & 1\end{array}$

FIG. 6. As in Fig. 5, but for 700-hPa geopotential height for R25 cases.

The GEFS mean CTEs for L25 and R25 cases are averaged as a function of forecast hour in Fig. 4a. The error bars, which represent the $95 \%$ confidence interval of the sample mean, indicate that both sets are significantly different from zero at $36 \mathrm{~h}$ in the forecast (Fig. 4a). The CTEs grow steadily afterward, with both sets reaching $\sim 500 \mathrm{~km}$ by $120 \mathrm{~h}$. The ATEs for the R25 are significantly negative (slow-biased) and 100-200 km in magnitude after $72 \mathrm{~h}$, while those of the L25 are not significantly different from zero at any forecast hour (Fig. 4b). Hence, most of the R25 cases also develop slow biases as the TCs move westward in the tropics.

TC intensity may be contributing to these track errors by affecting the TC's depth and hence how winds aloft steer the TC (Colby 2015; Brennan et al. 2015), or by affecting the TC's radius and its interactions with adjacent circulations (Galarneau and Davis 2013). The best-track maximum surface wind speeds for the R25 cases are $4-7 \mathrm{~m} \mathrm{~s}^{-1}$ higher than the L25 cases during the first $72 \mathrm{~h}$, though the difference is not statistically significant at the $95 \%$ level (Fig. 4c). The GEFS mean has a more negative (weak) bias throughout the forecasts of R25 cases, but the difference is again not significant (Fig. 4d). Thus, the relationship between TC maximum wind speed and the development of large left- or right-of-track errors in this study is not conclusive.

The ECMWF ensemble mean CTEs are compared with the GEFS for the same R25 and L25 cases (Fig. 4e). For the R25 cases, the GEFS sample-average CTE is $350 \mathrm{~km}$ larger than the ECMWF by $120 \mathrm{~h}$. Meanwhile, for the L25 cases, the GEFS is $200 \mathrm{~km}$ larger than the ECMWF by $120 \mathrm{~h}$. The GEFS is at least $100 \mathrm{~km}$ larger than the ECMWF in 31 of the 36 R25 cases, as compared with 22 of the 38 L25 cases (not shown). Thus, the ECMWF more consistently outperforms the GEFS in R25 cases than L25 cases.

\section{b. Large-scale error evolution of L25 cases}

The composited steering environments of the different GEFS cases are analyzed, starting with the L25 cases. On average, the largest height and steering-flow errors near the TC first develop at $\sim 300-\mathrm{hPa}$ in the L25 cases (not shown). Figure 5 thus shows the L25 case best-trackrelative composites of standardized differences in the 300-hPa geopotential height. The differences are calculated by subtracting the four rightmost GEFS members from the four leftmost members. The 850-200-hPa environmental steering flow is calculated following Galarneau and Davis (2013), removing the member TC winds within 

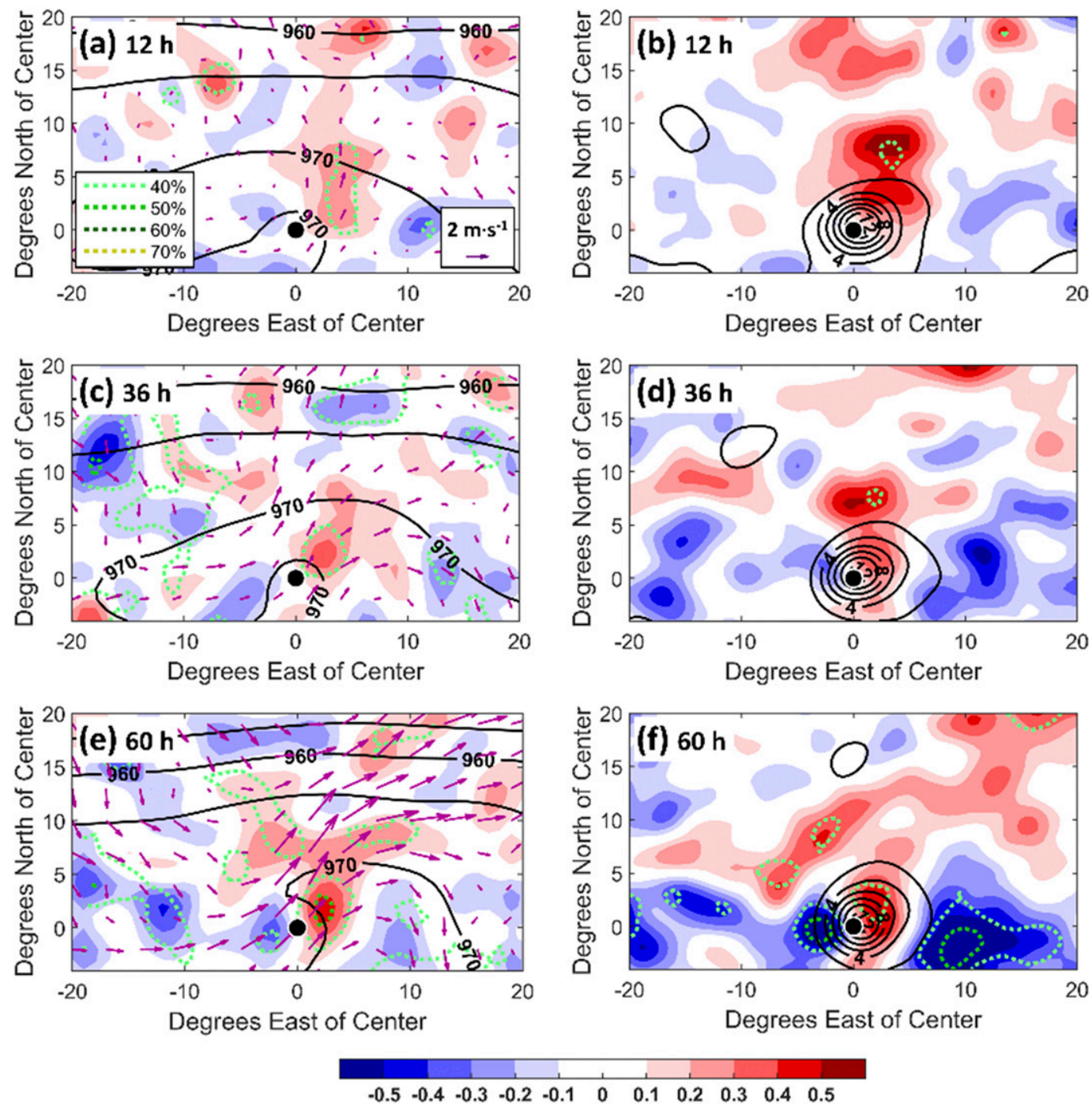

FIG. 7. TC-relative composites of standardized differences in 300-200-hPa divergence (shaded), differences in 300-200-hPa winds including the TC circulation (vectors), and 300-hPa geopotential heights (dam) of the full ensemble mean (black contours) of all R25 cases at (a) 12, (c) 36, and (e) $60 \mathrm{~h}$. Percentages of R25 cases in which the difference at each grid point is statistically significant are contoured in different shades from green to gold. (b),(d),(f) As in (a),(c), and (e), but showing standardized differences in precipitation rates, with the precipitation rates $\left[\mathrm{mm}(6 \mathrm{~h})^{-1}\right]$ of the full ensemble mean contoured in black. Black dots indicate the location of the TC center.

$5^{\circ}$ from each member TC position. At $12 \mathrm{~h}$ after model initialization (Fig. 5a), the leftmost members have geopotential heights that are +0.4 standard deviations $(2 \mathrm{~m})$ greater than the rightmost members over a broad region $5^{\circ}-10^{\circ}$ northwest of the TC. By $36 \mathrm{~h}$ (Fig. $5 \mathrm{~b}$ ), the leftmost members also have heights that are -0.4 standard deviations $(2-4 \mathrm{~m})$ lower than the rightmost to the northeast of the adjacent anticyclone. The positive height differences $10^{\circ}$ to the northwest of the TC are consistent with the leftmost members having a less amplified trough. While these positive differences have not changed much compared to $12 \mathrm{~h}$, their combination with the developing negative differences $10^{\circ}$ east of the TC results in the leftmost members having weaker southerly steering winds near the TC. Between 48 (Fig. 5c) and $60 \mathrm{~h}$ (Fig. 5d), the positive height differences between the approaching trough and TC remain constant, but the negative height differences to the east of the anticyclone grow to -0.6 standard deviations $(6 \mathrm{~m})$. The positive height differences to the west of the TC and negative height differences to the east result in steering winds that are $\sim 1 \mathrm{~m} \mathrm{~s}^{-1}$ weaker in the leftmost members. However, the height differences at these forecast hours are significant in less than $40 \%$ of L 25 cases. These composite differences change little in magnitude afterward (not shown), at which point the average CTE has exceeded $200 \mathrm{~km}$. 

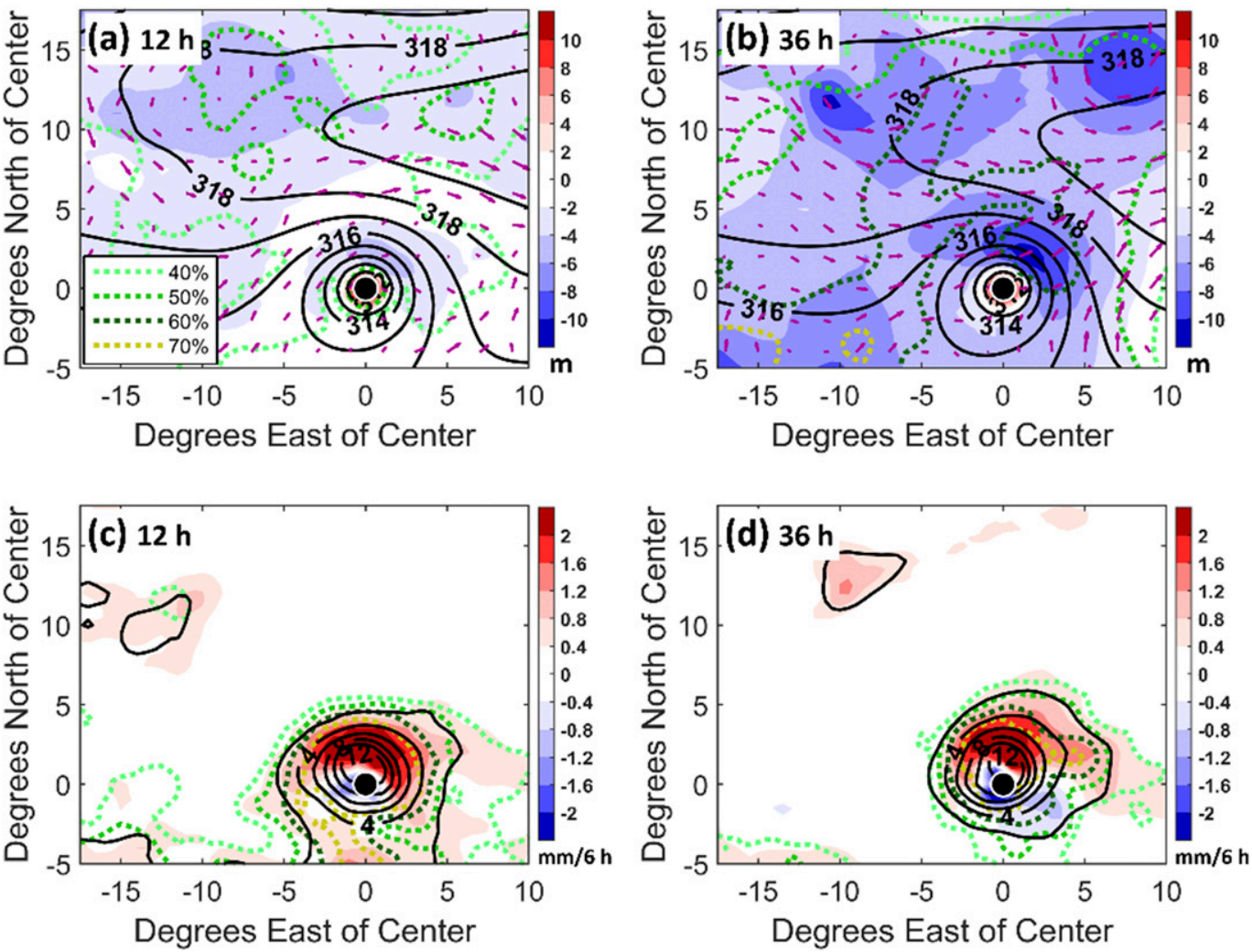

FIG. 8. TC-relative composites of GEFS - ECMWF differences (not standardized) in 700-hPa geopotential height (shaded) for R25 cases at (a) 12 and (b) $36 \mathrm{~h}$. Black contours are the composited 700-hPa geopotential heights (dam) of the GEFS mean, and vectors indicate the GEFS - ECMWF differences in 850-200-hPa environmental steering flow (after removing the TC circulation). (c),(d) As in (a),(b), but for GEFS - ECMWF differences in precipitation rate, with precipitation rates of the GEFS mean contoured in black. Percentages of R25 cases in which the difference at each grid point is statistically significant are contoured in different shades from green to gold. Black dots indicate the TC center.

The ECMWF ensemble fields were compared with the GEFS for the same L25 cases. However, similar to Fig. 5, the composites did not reveal significant differences (not shown).

\section{c. Large-scale error evolution of $R 25$ cases}

For the R25 cases, the largest height and steering-flow errors near the TC first develop $\sim 700 \mathrm{hPa}$ (not shown). Besttrack-relative standardized differences in $700-\mathrm{hPa}$ heights are calculated by subtracting the four leftmost GEFS members from the four rightmost GEFS members of each R25 case (Fig. 6). At $12 \mathrm{~h}$ (Fig. 6a), the geopotential heights within $10^{\circ}$ to the north of the TC are -0.6 standard deviations $(4 \mathrm{~m})$ lower in the rightmost members than in the leftmost members, the difference being statistically significant in up to $50 \%$ of the cases. This negative difference in height reaches -0.8 standard deviations $(7 \mathrm{~m})$ and is significant in $60 \%$ of the cases at $36 \mathrm{~h}$, consistent with the rightmost - leftmost 850-200-hPa steering-flow difference vectors forming a cyclonic circulation northwest of the TC (Fig. 6b). From 48 (Fig. 6c) to $60 \mathrm{~h}$ (Fig. 6d), the negative differences extend more than $10^{\circ}$ north of the TC.
During this time positive height differences, averaging +0.6 standard deviations $(2 \mathrm{~m})$, develop $\sim 10^{\circ}$ southeast of the TC in $40 \%$ of the cases. Consistent with the positive height differences, the $850-200-\mathrm{hPa}$ steering difference vectors also form an anticyclonic circulation to the southeast of the TC. The combination of the negative height anomalies to the northwest of the TC and the positive height anomalies to the southeast results in a southerly wind difference of 1-2 $\mathrm{m} \mathrm{s}^{-1}$, consistent with the rightmost members drifting more northward. By comparison, the L25 case composites of 700 -hPa heights were significantly less conclusive (not shown).

It is hypothesized that excessive height falls $\sim 5^{\circ}$ north of the TC may be caused by errors in upper-level divergence induced by convection in the TC's outer core. Figure 7 shows the rightmost - leftmost standardized differences in 300-200-hPa divergence and simulated precipitation rate for all R25 events, with the differences averaged in the TCrelative framework to minimize signals caused by TC position differences. Note the differences are calculated after taking the layer average. At $12 \mathrm{~h}$, there are differences in divergence $>+0.2$ standard deviations within $5^{\circ}$ east of 

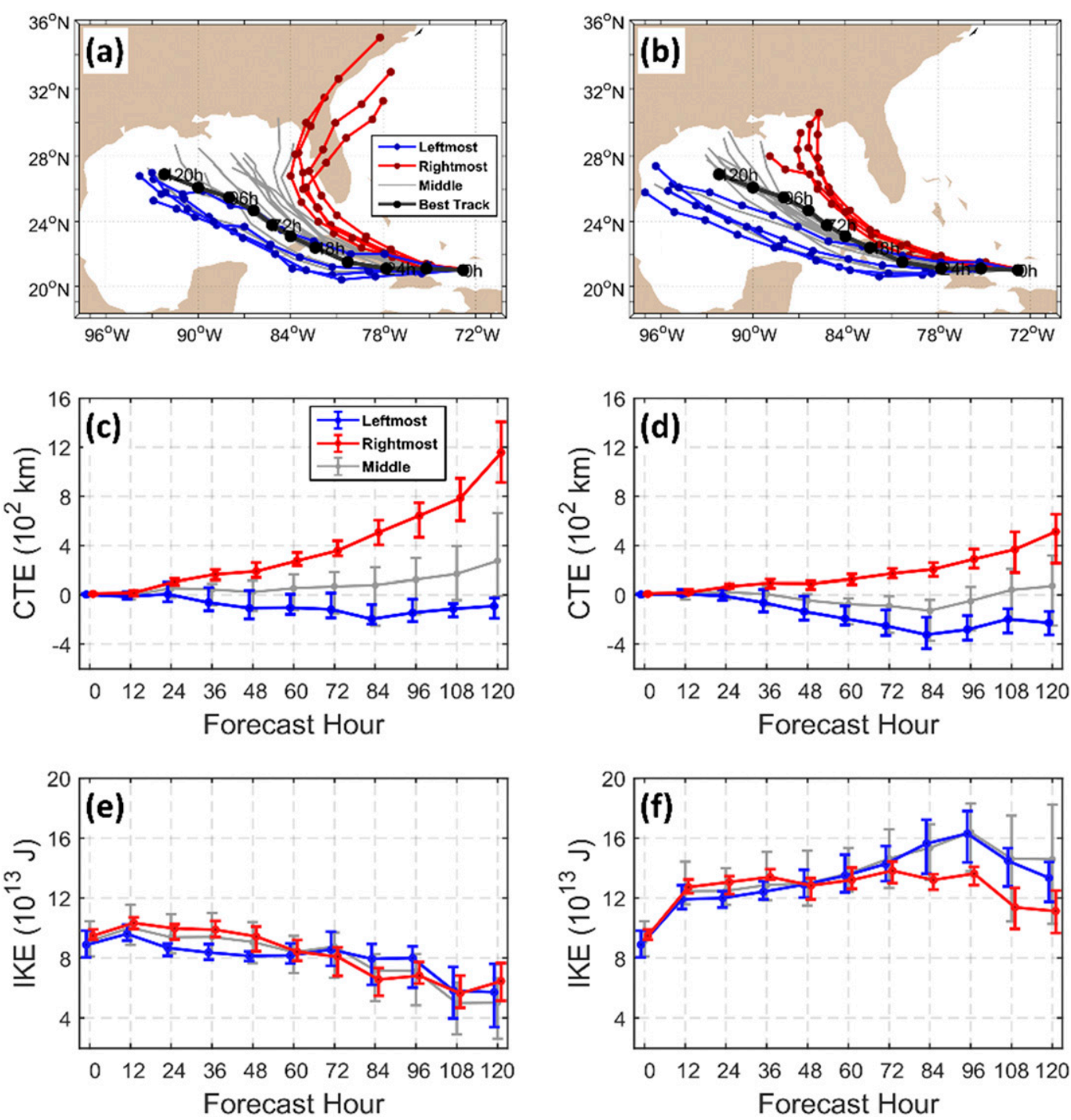

FIG. 9. (a) GEFS forecast tracks for Ike (2008), initialized at 1200 UTC 7 Sep 2008, with the four leftmost and four rightmost members compared with all other members and the best track. Also shown are time series of GEFS member (c) CTEs and (e) IKE, with bars indicating the minimum and maximum values in each subset of members. (b),(d),(f) As in (a),(c), and (e), but for the WRF $36 \mathrm{~km}$.

the TC (Fig. 7a). This positive divergence difference is significant in at least $40 \%$ of the cases. Between 36 (Fig. $7 \mathrm{c}$ ) and $60 \mathrm{~h}$ (Fig. 7e), the positive differences in divergence $\sim 3^{\circ}$ north and east of the TC increase from +0.3 to +0.4 standard deviations, reaching statistical significance in $50 \%$ of the cases Thus, part of the underprediction in local heights north of the TC may be caused by mass removal throughout the column driven by divergence aloft, which are quantified in section $3 \mathrm{~d}$.

Meanwhile, at $12 \mathrm{~h}$ (Fig. 7b), the standardized differences in precipitation rate are already positive and significant in $40 \%$ of cases over a region within $10^{\circ}$ north of the TC, exceeding +0.5 standard deviations $\left[1 \mathrm{~mm}(6 \mathrm{~h})^{-1}\right]$ in magnitude. The positive difference persists between 12 and $36 \mathrm{~h}$ (Fig. 7d). By $60 \mathrm{~h}$ (Fig. 7f), there is another area of positive differences $\sim 10^{\circ}$ northwest of the TC. This region is south of a small closed contour of $2 \mathrm{~mm}(6 \mathrm{~h})^{-1}$ precipitation rates $13^{\circ}$ north of the TC center and is likely associated with another TC or low pressure center in several of the cases (not shown). Negative differences also develop $5^{\circ}-10^{\circ}$ east of the TC, likely associated with convection in the deep tropics (not shown). The less extensive precipitation and divergence north of the leftmost members is more consistent with reanalysis datasets (not shown).

The ECMWF ensemble mean is compared with the GEFS for the same R25 cases. The differences in these plots are from two separate ensembles and are thus not standardized. At $12 \mathrm{~h}$, the GEFS mean 700-hPa heights are 2$3 \mathrm{~m}$ lower than the ECMWF over two regions: one located $5^{\circ}-12^{\circ}$ northwest of the TC center and another within $5^{\circ}$ 
north-northeast of the TC center (Fig. 8a). These height differences are significant in more than $50 \%$ of the R25 cases. The differences north of the TC and along the western extent of the ridge grow to $4-5 \mathrm{~m}$ and are significant in more than $60 \%$ of the cases by $36 \mathrm{~h}$ (Fig. $8 \mathrm{~b}$ ). The environmental steering difference vectors form a cyclonic circulation centered $10^{\circ}-15^{\circ}$ northwest of the TC.

The larger height falls north of the GEFS TC at $12-36 \mathrm{~h}$ are consistent with the GEFS having $2 \mathrm{~mm}(6 \mathrm{~h})^{-1}$ higher rainfall rates located $3^{\circ}-5^{\circ}$ north of the TC center at $12 \mathrm{~h}$ (Fig. 8c). These positive rainfall differences are significant in more than $50 \%$ of the cases. The differences are also significantly positive $12^{\circ}-15^{\circ}$ northwest of the TC in $30 \%-40 \%$ of the cases, associated with another low pressure center. The positive differences up to $6^{\circ}$ north of the TC persist through $36 \mathrm{~h}$ in $50 \%$ of the cases (Fig. 8d). Thus, consistent with the rightmost-leftmost member differences in Figs. 6 and 7, the smaller track errors of the ECMWF are associated with the model having less convection north of the TC. The reduced convection and upper-level divergence do not locally weaken the steering ridge as much as the GEFS. Thus, the ECMWF TC tracks farther southwest, consistent with a smaller right-of-track bias in Fig. 4e.

The hypothesis about the role of TC's outer-core convection in eroding the subtropical ridge is analyzed in the next two sections using variable-resolution WRF simulations. The simulations are performed for two cases that have 700-hPa height differences similar to the composites: Ike (2008) and Irma (2017). Irma (2017) is not in the original dataset, but it represents a more recent CTE case.

\section{d. Ike (2008) analysis}

The largest right-of-track bias for Ike $(370 \mathrm{~km}$ at $120 \mathrm{~h})$ is from the GEFS's 1200 UTC 7 September 2008 forecast cycle. The $36-\mathrm{km}$ WRF forecast tracks are compared with those of the GEFS members used as initial and lateral boundary conditions (Fig. 9). The leftmost and rightmost members in this section are defined relative to the GEFS CTEs at $120 \mathrm{~h}$. Ike's best track initially moves westward, shifts slightly north of west by $\sim 36 \mathrm{~h}$, and crosses over Cuba and into the Gulf of Mexico by $60 \mathrm{~h}$ (Fig. 9a). The GEFS's four rightmost members curve too far to the northeast, making landfall over the west coast of Florida by 84-96 h. The GEFS leftmost members closely follow the best track, drifting only $\sim 100 \mathrm{~km}$ too far to the south. Almost all $36-\mathrm{km}$ WRF members track southwest of their GEFS counterparts, with the rightmost members curving toward the Florida Panhandle and Louisiana (Fig. 9b).

The CTEs of the GEFS rightmost members diverge from all other members at 24-36 h (Fig. 9c). The error bars in this section are the minimum and maximum values within each subset of members. All members have right-of-track biases of only $\sim 10 \mathrm{~km}$ at $0 \mathrm{~h}$, such that the subsequent separation of tracks is not clearly correlated with the initial TC positions. At $120 \mathrm{~h}$, the ensemble mean CTE of the WRF is $270 \mathrm{~km}$ (60\%) less right of track than the GEFS (Fig. 9d). The range of 120 -h CTEs is $\sim 980 \mathrm{~km}$ in the WRF and $\sim 1600 \mathrm{~km}$ in the
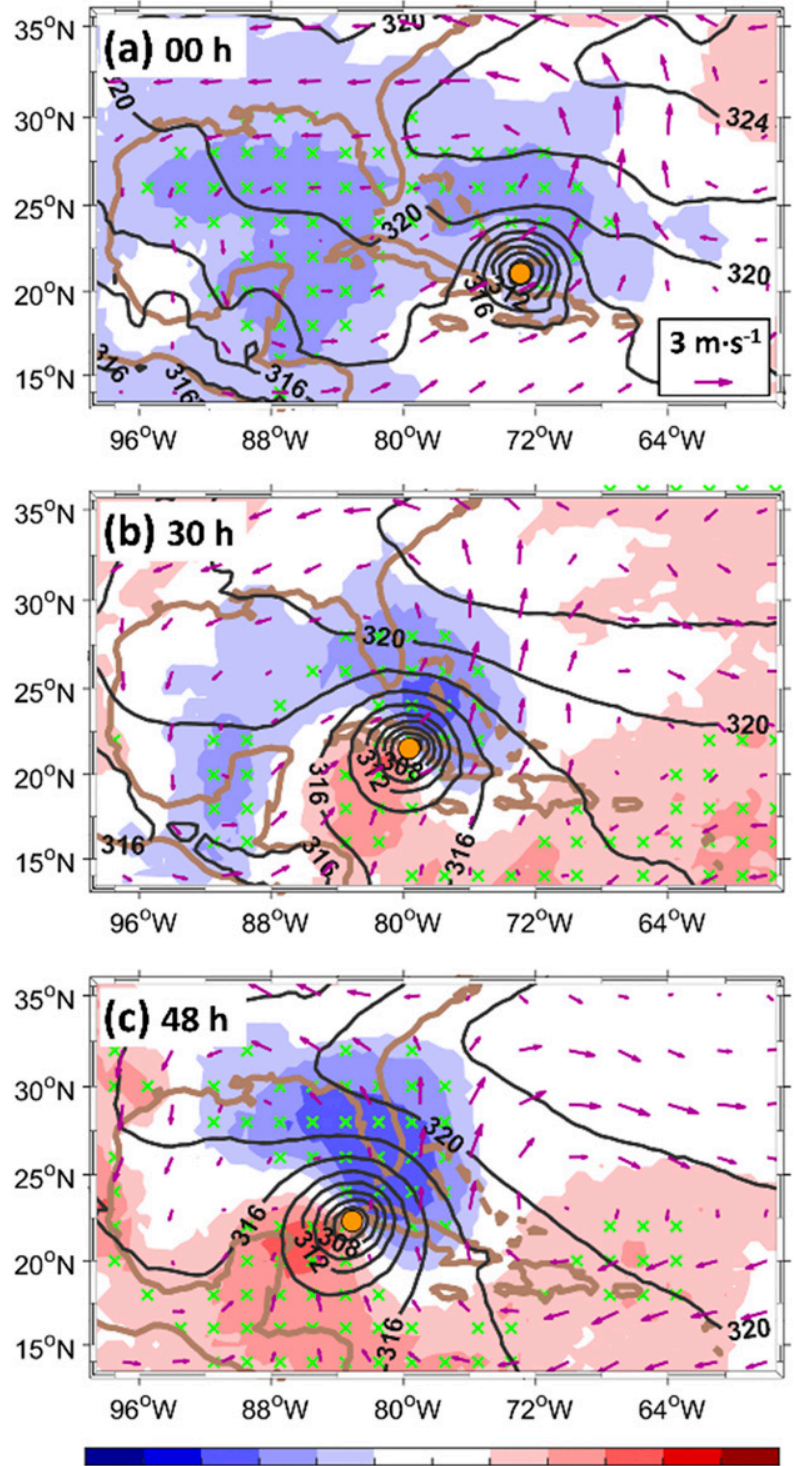

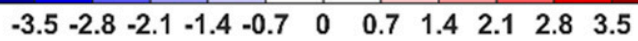

FIG. 10. The 36-km WRF rightmost - leftmost member standardized differences in 700-hPa geopotential height (shaded) and 850-200-hPa environmental steering flow after removing the TC circulation (vectors) at (a) 0 , (b) 30 , and (d) $48 \mathrm{~h}$. Green crosses indicate regions where the height difference is statistically significant. The $700-\mathrm{hPa}$ heights of the full ensemble mean are contoured in black. The orange dot indicates the ensemble mean TC position.

GEFS. The source of these discrepancies is unclear and additional tests of different model physics did not yield more consistent tracks. However, the four rightmost (leftmost) members in GEFS are still among the four-six rightmost (leftmost) members in WRF. Thus, while the WRF ensemble envelope is smaller and shifted to the left, the order of ensemble members from leftmost to rightmost differs little from the GEFS. 

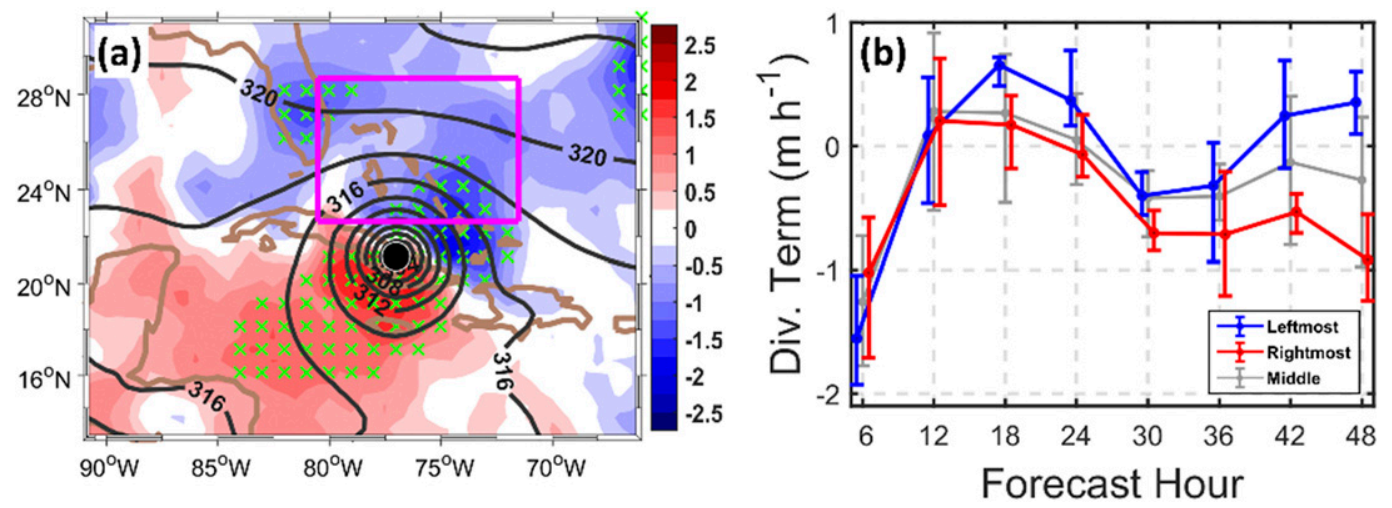

FIG. 11. (a) The 36-km WRF rightmost - leftmost member standardized differences in TC-centered $700-\mathrm{hPa}$ height tendency (shaded) at $18 \mathrm{~h}$, with regions of statistical significance marked with green crosses, the pink-outlined box indicating where quantities are area averaged relative to the TC center, and the $700-\mathrm{hPa}$ heights of the full ensemble mean contoured in black. (b) Area-averaged divergence term on the right-hand side of Eq. (3), with bars indicating the minimum and maximum values of each subset.

All members in both the WRF and GEFS underpredict Ike's maximum surface wind speed, albeit the WRF winds are $\sim 5 \mathrm{~m} \mathrm{~s}^{-1}$ faster than the GEFS during the first $12 \mathrm{~h}$ (not shown). There is no distinction between the wind speeds of the leftmost and rightmost members of either model. However, there are differences in the integrated kinetic energy, which is approximated following Powell and Reinhold (2007):

$$
\text { integrated kinetic energy }=\int_{V} \frac{1}{2} \rho U^{2} d V,
$$

where $\rho$ is the air density (assumed to be $1 \mathrm{~kg} \mathrm{~m}^{-3}$ ) and $U$ is the model $10-\mathrm{m}$ wind speed; $V$ is a volume of unit depth, evaluated within $8^{\circ}$ of the TC center and at all grid points where $U$ is at least $10 \mathrm{~m} \mathrm{~s}^{-1}$. The rightmost members in GEFS have $0.3-2 \mathrm{TJ}(5 \%-15 \%)$ more energy than the leftmost between 24 and $48 \mathrm{~h}$ (Fig. 9e). In WRF, the mean energy of the rightmost members is $\sim 1 \mathrm{TJ}(\sim 9 \%)$ greater than the leftmost at $24-36 \mathrm{~h}$, although the two subsets have overlapping values (Fig. 9f). The difference in energy likely corresponds to the wind fields of the rightmost member TCs expanding after $24 \mathrm{~h}$. There may also be impacts from Cuba's terrain, such that the maximum winds of the rightmost members are stronger because their cores are farther north over water. However, it is not evident whether this relationship is consistent with the TC's outer core feeding back to the steering environment.

The 36-km WRF rightmost - leftmost member standardized differences in best-track-centered $700-\mathrm{hPa}$ geopotential height are plotted in Fig. 10. At $0 \mathrm{~h}$ (Fig. 10a), Ike is embedded in the southwestern flank of a subtropical ridge, with its centroid $20^{\circ}$ northeast of Ike's position. The rightmost members have heights that are up to -1.5 standard deviations $(5-10 \mathrm{~m})$ lower than the leftmost members over a region stretching up to $15^{\circ}$ north and west of Ike. This negative height difference is consistent with the
850-200-hPa environmental steering (i.e., no TC circulation within $5^{\circ}$ of the TC center) difference vectors forming a cyclonic circulation over this region. At $30 \mathrm{~h}$ (Fig. 10b), the negative height differences northwest of Ike decrease in coverage, though the steering difference vectors still form a cyclonic circulation over the Gulf. Meanwhile, small positive height differences of +1 standard deviation (1-5 m) begin to develop $10^{\circ}-20^{\circ}$ to the southeast of Ike. By $48 \mathrm{~h}$ (Fig. 10c), the negative height differences north of Ike grow to -2 standard deviations $(15 \mathrm{~m})$, while the positive differences to the east decrease and approach the Dominican Republic. Thus, the rightmost members have $1-2 \mathrm{~m} \mathrm{~s}^{-1}$ more southwesterly steering near Ike throughout much of the forecast, resulting in a greater right-of-track error. The height differences in these plots resemble those composited in Fig. 6.

The connection between upper-level divergence and heights north of Ike is quantified using the terms from the height tendency equation [Eq. (3)]. The 30-min model output frequency is used for additional calculations. The $z_{2}$ height tendencies at an isobaric surface $p_{2}$ are diagnosed following Steenburgh and Holton (1993):

$$
\frac{\partial z_{2}}{\partial t}=-\frac{R}{g} \int_{p_{s}}^{p_{2}} \frac{\partial T_{v}}{\partial t} \partial \ln p+\frac{R T_{v}\left(p_{s}\right)}{p_{s} g} \frac{\partial p_{s}}{\partial t}
$$

where $p_{s}$ is the surface pressure; $T_{v}$ is the virtual temperature; and $R$ and $g$ are the gas constant for dry air and gravitational acceleration, respectively. The first right-hand-side term is the vertically integrated temperature tendency below $p_{2}$. The second term is the surface pressure tendency, which responds to net mass divergence in the column extending from the surface to the top of the atmosphere. Results in this study converged for intervals $\partial t$ as small as $30 \mathrm{~min}$.

When analyzing the rightmost-leftmost 700 -hPa height tendencies at $18 \mathrm{~h}$ (Fig. 11a), it is apparent that much of the difference occurs inside of $7^{\circ}$ north and east of Ike. 

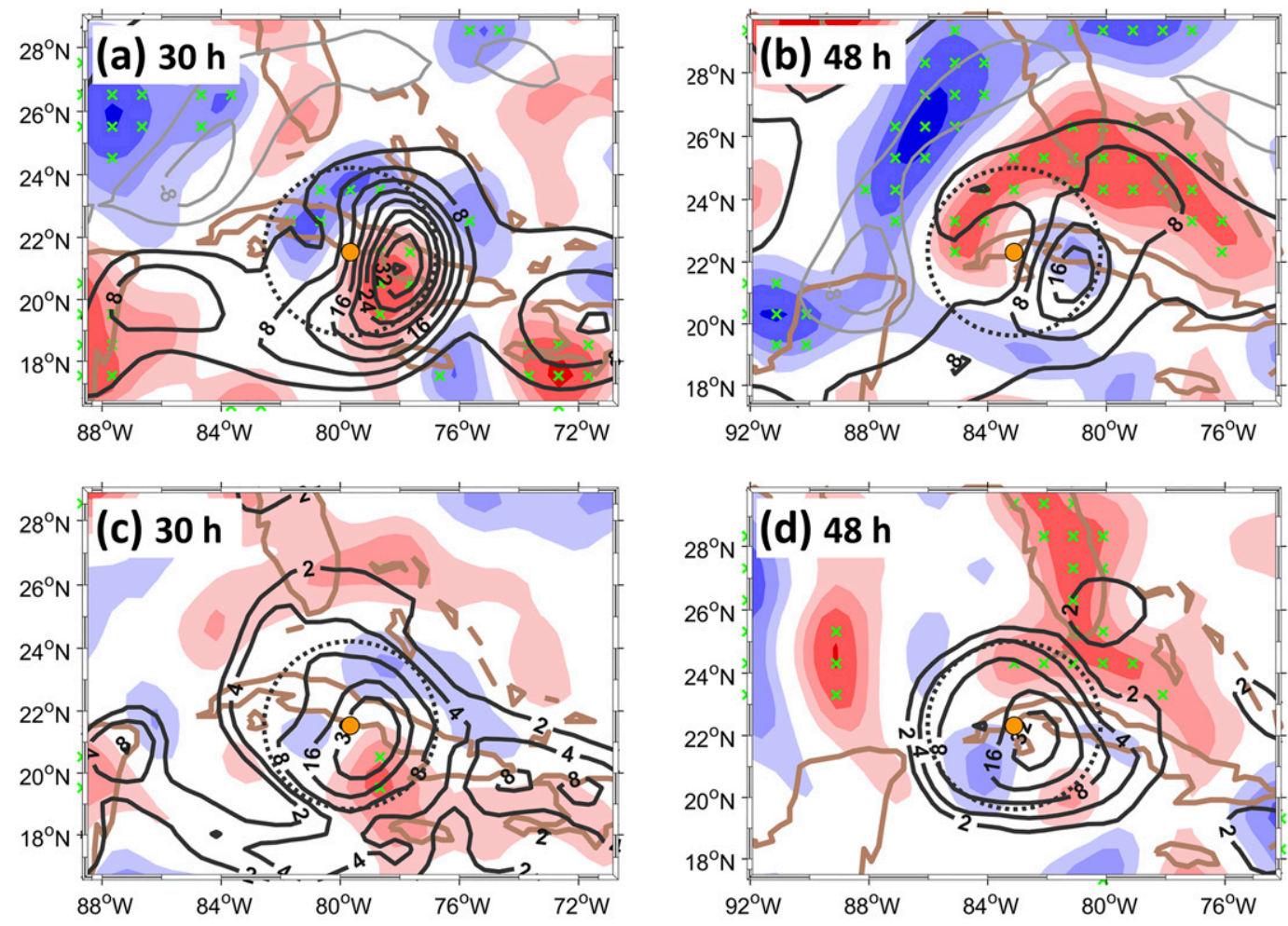

$\begin{array}{lllllllllll}-3.5 & -2.8 & -2.1 & -1.4 & -0.7 & 0 & 0.7 & 1.4 & 2.1 & 2.8 & 3.5\end{array}$

FIG. 12. The 36-km WRF rightmost - leftmost standardized differences in TC-centered 300-200-hPa divergence (shaded) at (a) 30 and (b) $48 \mathrm{~h}$, with positive and negative divergence of the full ensemble mean contoured every $10^{-5} \mathrm{~s}^{-1}$ in black and gray, respectively. (c),(d) As in (a) and (b), but with precipitation-rate differences shaded and ensemble mean precipitation rates contoured in millimeters per $6 \mathrm{~h}$ in black. Green crosses indicate regions where the differences are statistically significant. Orange dots indicate the TC center, and the black dashed circle is the $300-\mathrm{km}$ radius from the center.

The terms are thus area-averaged within the pink box in Fig. 11a, which is positioned relative to the TC center of each member and follows the TC with time. The box encompasses the evolving negative height differences generally north of the TC over time. The divergence term switches from negative at $6 \mathrm{~h}$ to positive at $12-18 \mathrm{~h}$, coinciding with the TC interacting with Cuba's terrain (Fig. 11b). The rightmost members are then up to $1 \mathrm{~m} \mathrm{~h}^{-1}$ $(100 \%)$ more negative than the leftmost, especially by $42-48 \mathrm{~h}$. The temperature term has a much smaller contribution to the height tendency throughout the forecast (not shown). Thus, the greater height falls north of the rightmost members are likely associated with locally enhanced divergence aloft.

The difference in upper-level divergence over this region is hypothesized to be associated with convective precipitation. The TC-centered standardized differences in 300-200-hPa divergence indicate that the rightmost members have +2 standard deviations $\left(\sim 1.3 \times 10^{-5} \mathrm{~s}^{-1}\right)$ more divergence than the leftmost members within $3^{\circ}$ southeast of the TC center at $30 \mathrm{~h}$ (Fig. 12a). By $48 \mathrm{~h}$, the rightmost members have -3 standard deviations $\left(6 \times 10^{-6} \mathrm{~s}^{-1}\right)$ less divergence $5^{\circ}$ northwest of the TC and +2 standard deviations $\left(8 \times 10^{-6} \mathrm{~s}^{-1}\right)$ more divergence $3^{\circ}-6^{\circ}$ northeast of the TC (Fig. 12b). The latter anomaly had expanded and pivoted counterclockwise around the TC between 30 and $48 \mathrm{~h}$. This positive divergence is associated with the rightmost members having +1 standard deviation $\left[\sim 2 \mathrm{~mm}(6 \mathrm{~h})^{-1}\right]$ higher precipitation rates over a region that is $3^{\circ}$ southeast of the TC at $30 \mathrm{~h}$ (Fig. 12c) and then moves to $6^{\circ}$ north of the TC by $48 \mathrm{~h}$ (Fig. 12d). Thus, the increase in rightmost member precipitation is coupled with greater divergence aloft, corresponding to the larger $700-\mathrm{hPa}$ height falls northeast of Ike after $30 \mathrm{~h}$.

Additional tests ran the 36-km WRF with the Tiedtke convective precipitation scheme in place of the SAS scheme. Only the four rightmost members are compared in Fig. 13. The Tiedtke scheme takes all four members farther east than SAS, having three members make landfall over the western coast of Florida (Fig. 13a). While the CTEs overlap between some members of the two sets, each member using Tiedtke is at least $50 \mathrm{~km}$ more right of track than the same member using SAS by 

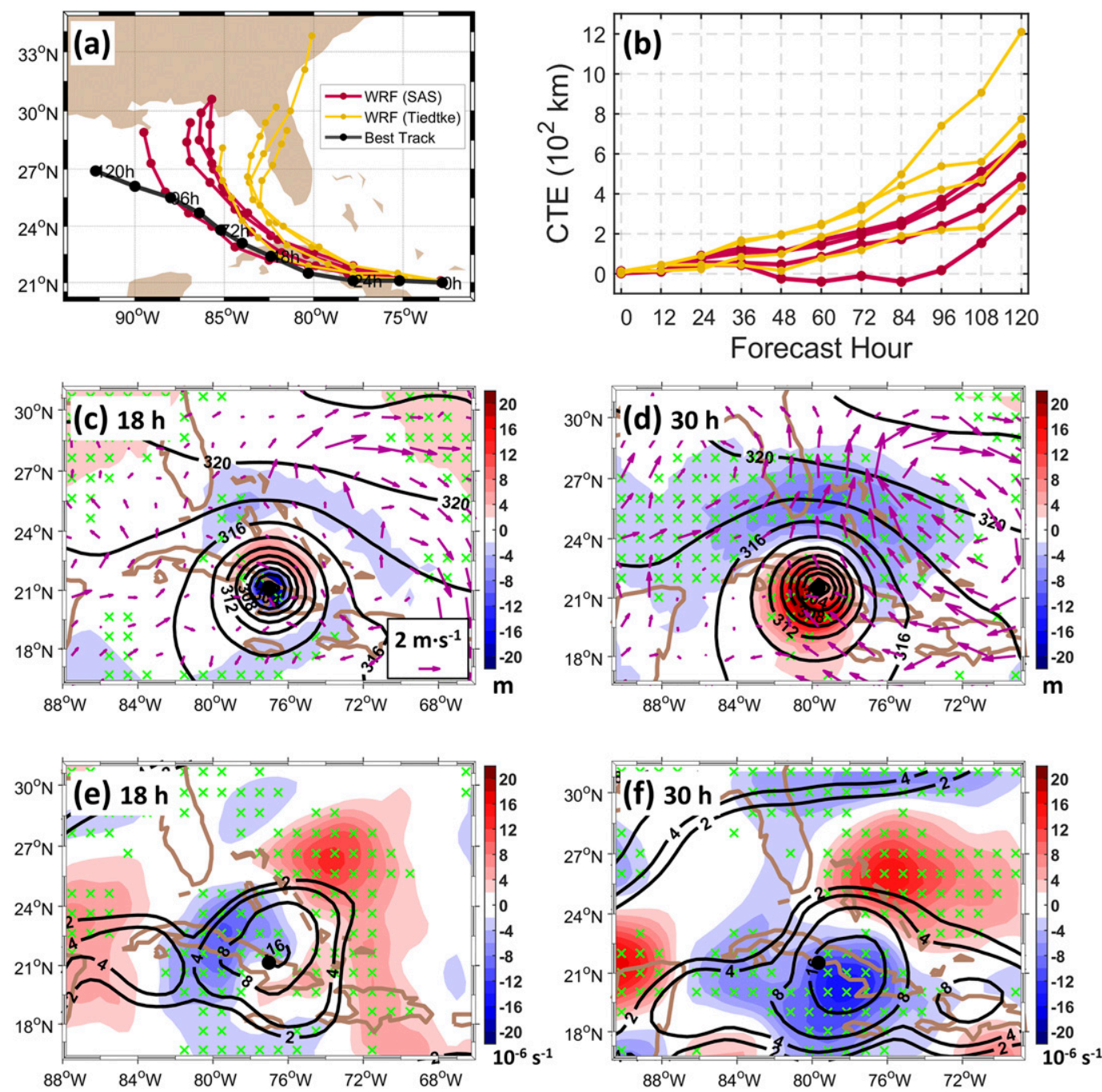

FIG. 13. Rightmost member (a) tracks and (b) CTEs of 36-km WRF runs using the SAS and Tiedtke schemes. WRF-Tiedtke - WRF-SAS differences (not standardized) in TC-centered 700-hPa geopotential heights (shaded) at (c) 18 and (d) $30 \mathrm{~h}$. Black contours are the 700-hPa geopotential heights (dam) of the WRF-SAS mean and vectors are differences in 850-200-hPa environmental steering flow (after removing the TC circulation). (e),(f) As in (c) and (d), but for differences in 300-200-hPa divergence, with divergence $\left(10^{-6} \mathrm{~s}^{-1}\right)$ of the WRF-SAS contoured in black. Regions where all rightmost members of WRF-SAS are larger or smaller than WRF-Tiedtke are marked with green crosses.

$48 \mathrm{~h}$ (Fig. 13b). The mean difference grows to $120-560 \mathrm{~km}$ by $120 \mathrm{~h}$.

The TC-centered fields of the rightmost members using SAS are subtracted from those using Tiedtke. As in the comparison of the GEFS and ECMWF, these differences are between two different ensembles and are thereby not standardized. The $700-\mathrm{hPa}$ heights $4^{\circ}-6^{\circ}$ north of Ike are lower in all Tiedtke members at $18 \mathrm{~h}$ (Fig. 13c). These negative differences in height expand in coverage and grow to more than $8 \mathrm{~m}$ in magnitude by $30 \mathrm{~h}$ (Fig. 13d). Meanwhile, all members using Tiedtke also have more $300-200-\mathrm{hPa}$ divergence $3^{\circ}-5^{\circ}$ north and northeast of Ike between 18 (Fig. 13e) and $30 \mathrm{~h}$ (Fig. 13f). These differences in divergence are consistent with the Tiedtke runs having $50 \%-200 \%$ precipitation rates extending north of Ike (not shown). Thus, the growth of CTEs is sensitive to different convective schemes. The Tiedtke scheme generates more rainfall than the SAS scheme, as well as precipitation analyses (not shown), which causes more upper-level divergence and midlevel height falls northeast of Ike during the first $30 \mathrm{~h}$. These height falls then correspond to southwesterly steering errors that cause Ike to drift farther right of track.

The impact of model resolution is tested by adding the inner 12- and 4-km TC-following WRF nests. The SAS convective scheme is run on all but the $4-\mathrm{km}$ grid. 

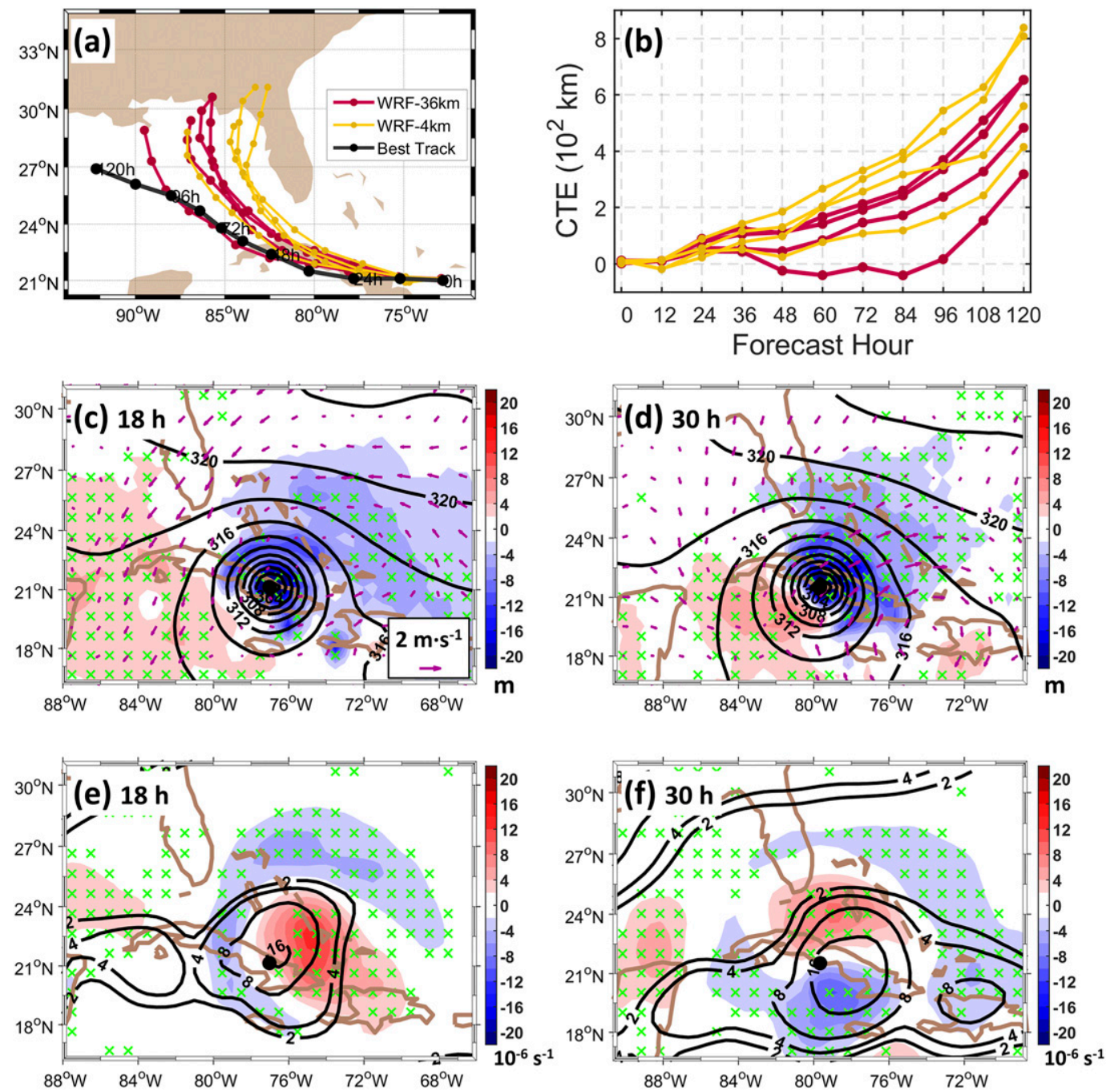

FIG. 14. Rightmost member (a) tracks and (b) CTEs of the 36-km WRF vs the 4-km WRF. WRF 4-km - WRF 36-km differences (not standardized) in TC-centered 700-hPa geopotential heights (shaded) at (c) 18 and (d) $30 \mathrm{~h}$. Black contours are the 700-hPa geopotential heights (dam) of the WRF-36km mean and vectors are differences in 850-200-hPa environmental steering flow (after removing the TC circulation). (e),(f) As in (c) and (d), but for differences in $300-200-\mathrm{hPa}$ divergence, with divergence $\left(10^{-6} \mathrm{~s}^{-1}\right)$ of the WRF $36 \mathrm{~km}$ contoured in black. Regions where all rightmost members of WRF $36 \mathrm{~km}$ are larger or smaller than WRF $4 \mathrm{~km}$ are marked with green crosses.

As with Figs. 13 and 14 only compares the rightmost members and all TC-centered differences plotted are not standardized. Each member in the 4-km ensemble is east of its respective counterpart in the $36-\mathrm{km}$ ensemble (Fig. 14a). This corresponds to the $4-\mathrm{km}$ member CTEs becoming $20-70 \mathrm{~km}$ more right of track by $48 \mathrm{~h}$ (Fig. 14b). The TC-centered $4-36-\mathrm{km}$ differences in $700-\mathrm{hPa}$ heights indicate that the 4-km has lower heights northeast of Ike and higher heights to the southwest at $18 \mathrm{~h}$ (Fig. 14c). The former is consistent with the $850-200-\mathrm{hPa}$ steering-flow difference vectors forming a cyclonic circulation. The negative height differences to the northeast are still present by $30 \mathrm{~h}$ (Fig. 14d). Meanwhile, the $4-\mathrm{km}$ has more 300 200-hPa divergence within $300 \mathrm{~km}$ east of northeast of the
TC center at $18 \mathrm{~h}$ (Fig. 14e). This region shifts farther north at $30 \mathrm{~h}$ (Fig. 14f) and is consistent with the 4-km having more rainfall north of Ike (not shown). Thus, the CTE is sensitive to horizontal resolution. However, the introduction of a 4-km nest with explicit convection degrades Ike's track forecast by generating more convection, upper-level divergence, and 700-hPa height falls northeast of Ike.

The excessive convection despite increased horizontal resolution may be contributed by other factors, such as the growth of initial condition errors. It was found that the rightmost WRF members had $\sim 5 \%-10 \%$ more initial conditional instability and moisture than the leftmost within the 900-700-hPa layer (not shown). However, the differences in the initial conditions are more clearly seen 

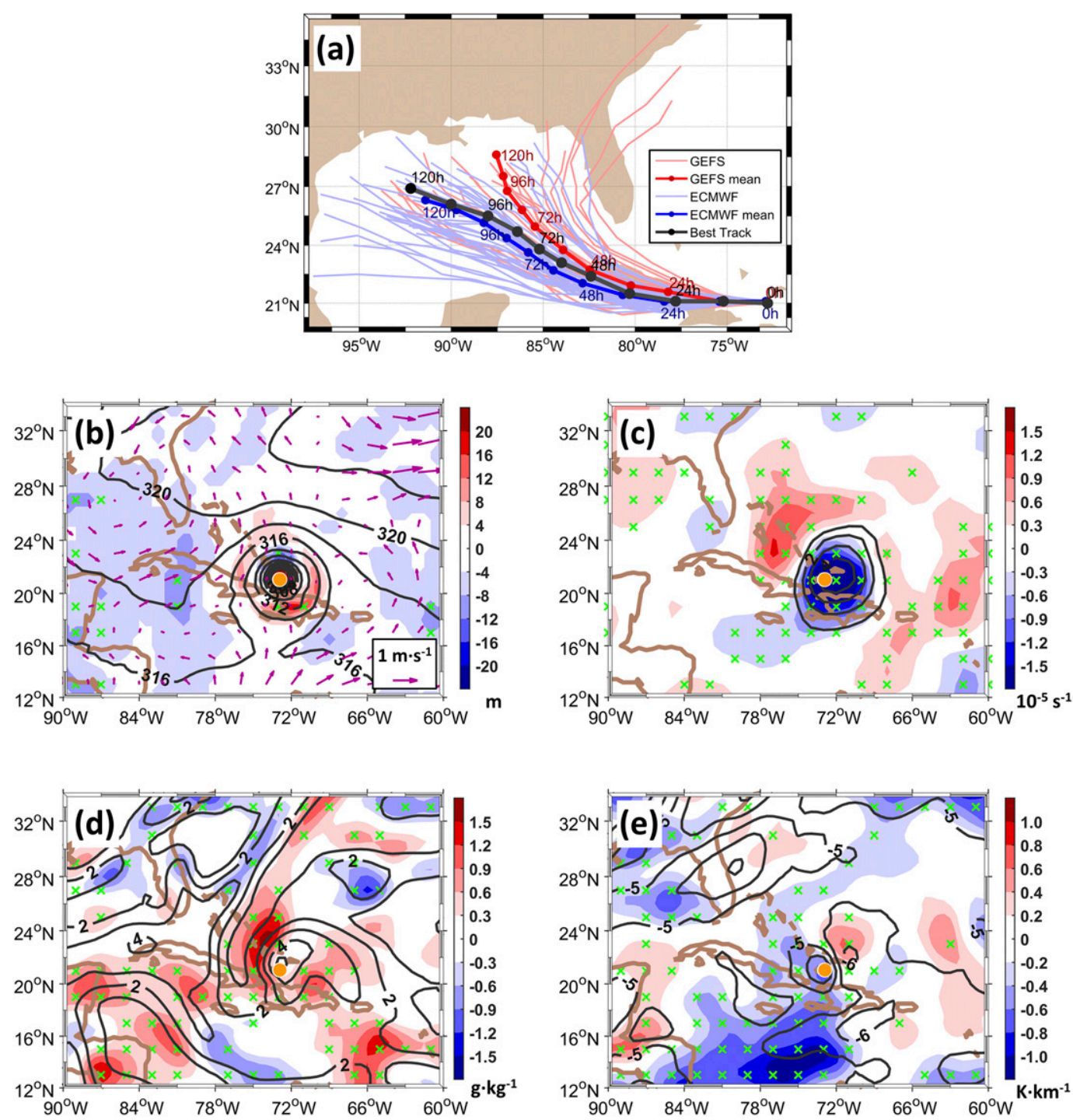

FIG. 15. (a) GEFS and ECMWF track forecasts for Ike, initialized at 1200 UTC 7 Sep 2008. (b) Initial GEFS - ECMWF mean differences in 700-hPa height (shaded), 700-hPa heights of the GEFS mean (black contours), and GEFS - ECMWF mean difference in 850-200-hPa environmental steering flow after removing the TC circulation (vectors). Green crosses mark regions where the height difference is statistically significant, and orange dots indicate the GEFS mean TC position. As in (b), but showing initial differences in (c) 300-200-hPa divergence, (d) 500-hPa specific humidity, and (e) 925-700-hPa lapse rate.

when comparing the GEFS with the ECMWF ensemble for the same 1200 UTC 7 September 2008 cycle. The ECMWF ensemble envelope is closely centered on the best-track position, with the ECMWF mean having near-zero CTE at $120 \mathrm{~h}$ (Fig. 15a). The differences between the GEFS and ECMWF mean tracks first develop at 12-24 h, at which point the GEFS starts to drift farther north. The GEFS - ECMWF mean 700-hPa height differences at $0 \mathrm{~h}$ indicate that the GEFS heights are initially $\sim 10 \mathrm{~m}$ lower than the ECMWF $\sim 10^{\circ}-15^{\circ}$ west and northwest of Ike and along the southwest extent of the ridge (Fig. 15b). The steeringflow difference vectors form a consistent cyclonic circulation north-northwest of Ike. At $0 \mathrm{~h}$, the GEFS also has larger
300-200-hPa divergence (Fig. 15c), more 500-hPa specific humidity (Fig. 15d), and steeper 925-700-hPa lapse rates (Fig. 15e) north-northwest of Ike. The ECMWF thus develops less aggressive outer-core convection than the GEFS during the first $24 \mathrm{~h}$, resulting in less upper-level divergence and midlevel height falls north of Ike (not shown). The ECMWF's ridge thereby remains stronger, correctly steering Ike farther westward.

\section{e. Irma (2017) analysis}

For Irma, the largest right-of-track bias $(400 \mathrm{~km}$ at $120 \mathrm{~h}$ ) is from the GEFS's 0000 UTC 7 September 2017 

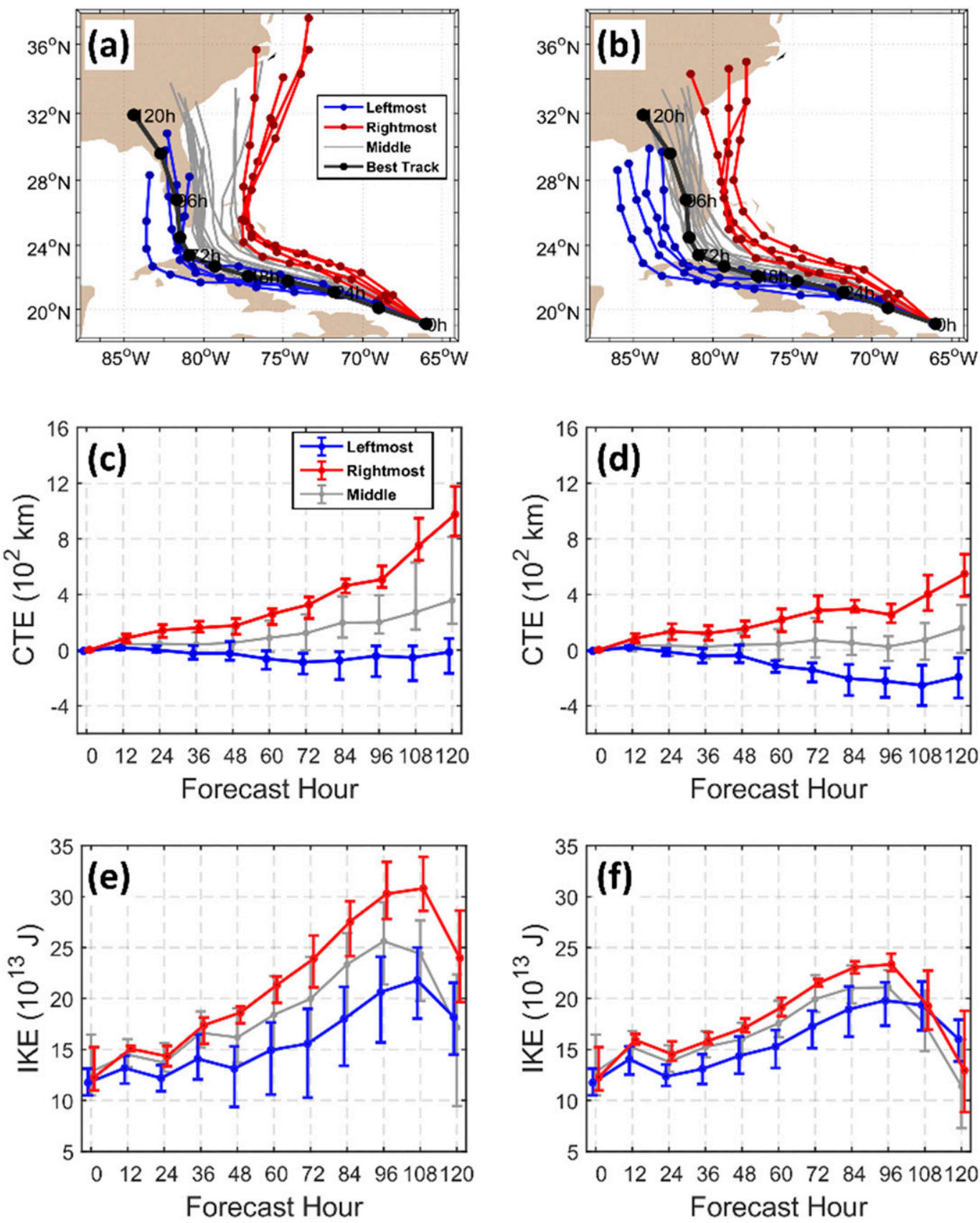

FIG. 16. (a) GEFS forecast tracks for Irma (2017), initialized at 0000 UTC 7 Sep 2017, with the four leftmost and four rightmost members compared with all other members and the best track. Also shown are time series of GEFS member (c) CTEs and (d) IKE, with bars indicating the minimum and maximum values in each subset. (b),(d),(f) As in (a), (c), and (e), but for the WRF $36 \mathrm{~km}$.

cycle. Irma's best track moves west-northwestward during the first $36 \mathrm{~h}$, slows down and turns northward at $\sim 72 \mathrm{~h}$, and makes landfall over southwestern Florida by $\sim 96 \mathrm{~h}$ (Fig. 16a). The four rightmost GEFS members drift $100-300 \mathrm{~km}$ too far to the north during the first $48 \mathrm{~h}$ before sharply turning north-northeastward. The leftmost GEFS members more closely follow the best track during the first $72 \mathrm{~h}$, although curving too slowly to the north afterward. Similar to Ike, the 36-km WRF tracks for Irma are south and west of their GEFS counterparts (Fig. 16b).

The CTEs of all rightmost GEFS members are at least $50 \mathrm{~km}$ larger than the leftmost members by $36 \mathrm{~h}$ (Fig. 16c). From 36 to $120 \mathrm{~h}$, the rightmost GEFS members become steadily more right of track at rates of $\sim 200 \mathrm{~km} \mathrm{day}^{-1}$, 

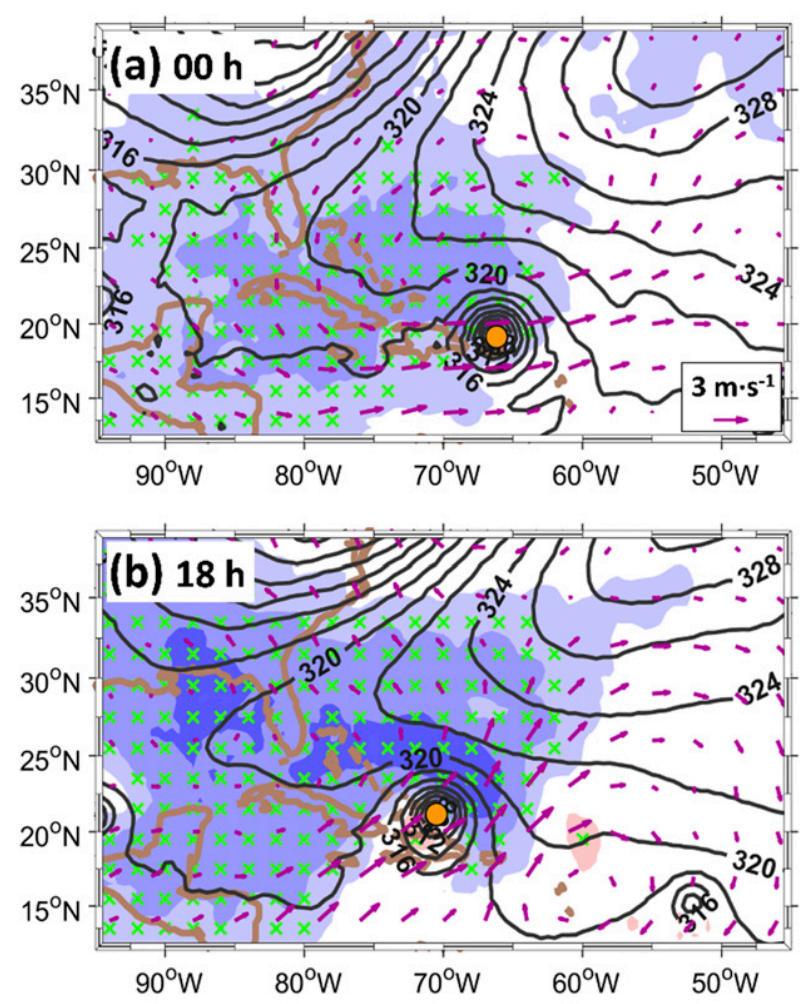

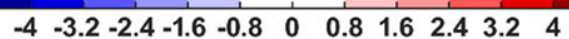

FIG. 17. The 36-km WRF rightmost - leftmost member standardized differences in $700-\mathrm{hPa}$ geopotential height (shaded) and 850-200-hPa environmental steering flow after removing the TC circulation (vectors) at (a) 0 and (b) $18 \mathrm{~h}$. Green crosses indicate regions where the height difference is statistically significant. The 700-hPa heights of full ensemble mean are contoured in black. Orange dots indicate the ensemble mean TC position.

while the leftmost become left of track at $\sim 50 \mathrm{~km} \mathrm{day}^{-1}$. The 120-h CTE of the WRF ensemble mean is $240 \mathrm{~km}(\sim 40 \%)$ less than the GEFS mean (Fig. 16d). The range of 120-h CTEs is only $1000 \mathrm{~km}$ in the WRF, as compared with $1350 \mathrm{~km}$ in the GEFS. However, the leftmost-to-rightmost order of members changes little, with the four rightmost members in GEFS still being rightmost in WRF.

The TC's maximum surface wind speed is underpredicted by both GEFS and WRF (not shown). However, after $36 \mathrm{~h}$, the mean integrated kinetic energy of the GEFS rightmost members is $5 \mathrm{TJ}(40 \%)$ higher than the leftmost (Fig. 16e). In WRF, the rightmost members have $3 \mathrm{TJ}(\sim 20 \%)$ more energy than the leftmost by $48 \mathrm{~h}$ (Fig. 16f). This difference is likely due to the rightmost member TCs becoming broader, which may again reflect the extent of outer-core convection.

The 36-km WRF rightmost - leftmost standardized differences in $700-\mathrm{hPa}$ height and $850-200-\mathrm{hPa}$ steering correspond to the differing member tracks. At $0 \mathrm{~h}$ (Fig. 17a), Irma is embedded in the southwest extension of a subtropical ridge, which is centered $20^{\circ}-25^{\circ}$ to the northeast of Irma. The $700-\mathrm{hPa}$ heights $100-1000 \mathrm{~km}$ north and west of Irma are -1.5 standard deviations $(10-15 \mathrm{~m})$ lower in the rightmost members than the leftmost members. This negative height difference is consistent with a cyclonic wind difference over this region. Consequentially, the rightmost member winds steering Irma are $\sim 2 \mathrm{~m} \mathrm{~s}^{-1}$ less easterly than the leftmost. At $18 \mathrm{~h}$ (Fig. 17b), the negative height differences north and northwest of Irma grow to -2.5 standard deviations $(15-20 \mathrm{~m})$. The steering differences near Irma also increase, such that the rightmost member winds are $2-3 \mathrm{~m} \mathrm{~s}^{-1}$ more southwesterly than the leftmost. This weakness in the ridge persists in the rightmost members throughout the next $12-18 \mathrm{~h}$ (not shown).

The height tendency diagnostic of Eq. (3) was repeated for this case (not shown). Similar to Ike, the 700-hPa height changes north of Irma are largely driven by the divergence term, which is most negative in the rightmost members. This difference in divergence is mostly above $300 \mathrm{hPa}$, where the rightmost members have +1.5 standard deviations more divergence than the leftmost members $3^{\circ}-6^{\circ}$ northwest of Irma at $6 \mathrm{~h}$ (Fig. 18a). The larger divergence is consistent with the rightmost members also having +1.5 standard deviations [2-4 $\left.\mathrm{mm}(6 \mathrm{~h})^{-1}\right]$ higher rainfall along Irma's northern flank. The divergent outflow stretches farther northwestward of the rightmost members by $18 \mathrm{~h}$, interacting with a weak upper-level shortwave $8^{\circ}$ north of Irma (Fig. 18b). This expansion is also consistent with the rightmost members having +1.5 standard deviations $\left[1-3 \mathrm{~mm}(6 \mathrm{~h})^{-1}\right]$ more rainfall extending $5^{\circ}$ north and northwestward from Irma between 6 (Fig. 18c) and $18 \mathrm{~h}$ (Fig. 18d).

The effects of replacing the SAS convection scheme in the four rightmost members with the Tiedtke scheme were tested. The runs using the Tiedtke scheme gradually steers Irma farther east of Florida than the SAS scheme (Fig. 19a), resulting in CTEs $\sim 40$ and $\sim 200 \mathrm{~km}$ more right of track at 36 and $120 \mathrm{~h}$, respectively (Fig. 19b). The Tiedtke - SAS differences (not standardized) in 700-hPa height are negative to the northeast of Irma at $24 \mathrm{~h}$ (Fig. 19c), growing to $-6 \mathrm{~m}$ by $36 \mathrm{~h}$ (Fig. 19d). The $850-200-\mathrm{hPa}$ steering flow is $\sim 1 \mathrm{~m} \mathrm{~s}^{-1}$ more southwesterly near the rightmost member TCs by $36 \mathrm{~h}$. The lower heights are consistent with the Tiedtke runs having more 300-200-hPa divergence $3^{\circ}-5^{\circ}$ northwest of Irma at $24 \mathrm{~h}$ (Fig. 19e). These positive differences grow in coverage north of Irma by $36 \mathrm{~h}$ (Fig. 19f). The stronger divergence corresponds to more precipitation developing along Irma's northern outer core (not shown). Thus, the Tiedtke scheme strengthens the feedback between Irma's convection and the steering environment, resulting in a larger northeastward deflection than the SAS scheme.

Similar to Ike, the addition of 12- and 4-km nests cause Irma to drift $100-300 \mathrm{~km}$ farther right of track than in the $36-\mathrm{km}$ runs (not shown). The question about the role of initial conditions is then investigated once more. Focusing again on the $36-\mathrm{km}$ WRF runs using the SAS scheme, the precipitation rates north of Irma are larger in 

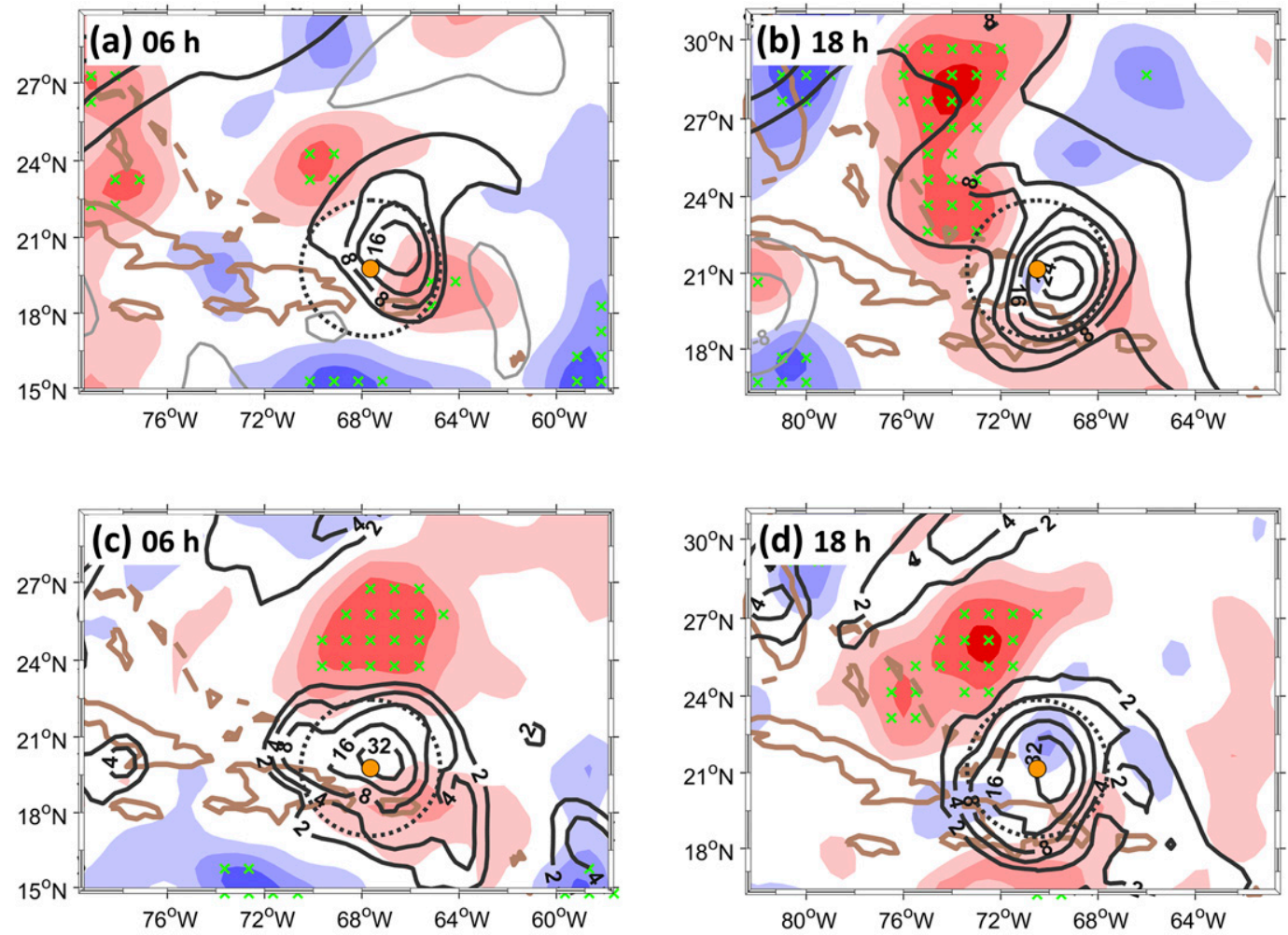

\section{$\begin{array}{lllllllllll}-2.5 & -2 & -1.5 & -1 & -0.5 & 0 & 0.5 & 1 & 1.5 & 2 & 2.5\end{array}$}

FIG. 18. The 36-km WRF rightmost - leftmost standardized differences in TC-centered 300-200-hPa divergence (shaded) at (a) 6 and (b) $18 \mathrm{~h}$, with positive and negative divergence of the full ensemble mean contoured every $10^{-5}$ per second in black and gray, respectively. (c),(d) As in (a) and (b), but with precipitation-rate differences shaded and ensemble mean precipitation rates contoured every millimeter per $6 \mathrm{~h}$ in black. Green crosses indicate regions where the differences are statistically significant. Orange dots indicate the TC center, and the black dashed circle is the $300-\mathrm{km}$ radius from the center.

the rightmost members at $6 \mathrm{~h}$ (Fig. 20a). Initial quantities are area-averaged within the dark green box encompassing this region. Between 800 and $600 \mathrm{hPa}$, the equivalent potential temperature of the rightmost members decreases $\sim 3 \mathrm{~K}(90 \%)$ more with height than the leftmost members, implying that the layer is more unstable (Fig. 20b). The initial moisture profile of the rightmost members is 0.4 $0.9 \mathrm{~g} \mathrm{~kg}^{-1}(3 \%-12 \%)$ more moist than the leftmost between 900 and $650 \mathrm{hPa}$, although the two subsets overlap (Fig. 20c). Thus, greater initial instability and moisture in the rightmost members likely promotes more convection and a greater feedback locally weakening the steering ridge.

The role of the initial conditions in Irma's track forecast is farther explored by comparing the original GEFS against the ECMWF ensemble. While the ECMWF mean track also drifts too far to the east after $72 \mathrm{~h}$ (Fig. 21a), the GEFS CTEs are $150 \mathrm{~km}$ larger at $120 \mathrm{~h}$ (Fig. 21b). At $0 \mathrm{~h}$, the GEFS 700 -hPa heights are $\sim 20 \mathrm{~m}$ lower than the ECMWF within $5^{\circ} \mathrm{N}$ of Irma (Fig. 21c). The GEFS heights are higher than the ECMWF over a large region south and southeast of Irma. The GEFS environmental steering flow near the TC is $\sim 1 \mathrm{~m} \mathrm{~s}^{-1}$ more southwesterly than the ECMWF. By $12 \mathrm{~h}$, the negative height differences north of Irma expand in coverage and appear farther north along the southwest extent of the ridge, corresponding to more cyclonic environmental steering differences compared to $0 \mathrm{~h}$ (Fig. 21d). The GEFS ensemble also initially has $\sim 1.2 \mathrm{~g} \mathrm{~kg}^{-1}(10 \%-15 \%)$ more $700-\mathrm{hPa}$ specific humidity within $5^{\circ} \mathrm{N}$ of Irma (Fig. 21e). These differences in humidity persist during the first $12 \mathrm{~h}$ (Fig. 21f) and are again consistent with the GEFS producing more convection north of the TC and upper-level divergence penetrating and weakening the ridge, resulting in the GEFS's larger track error.

\section{Summary and conclusions}

The regional flow patterns and processes associated with large 72-120-h CTEs of North Atlantic TC forecasts are 

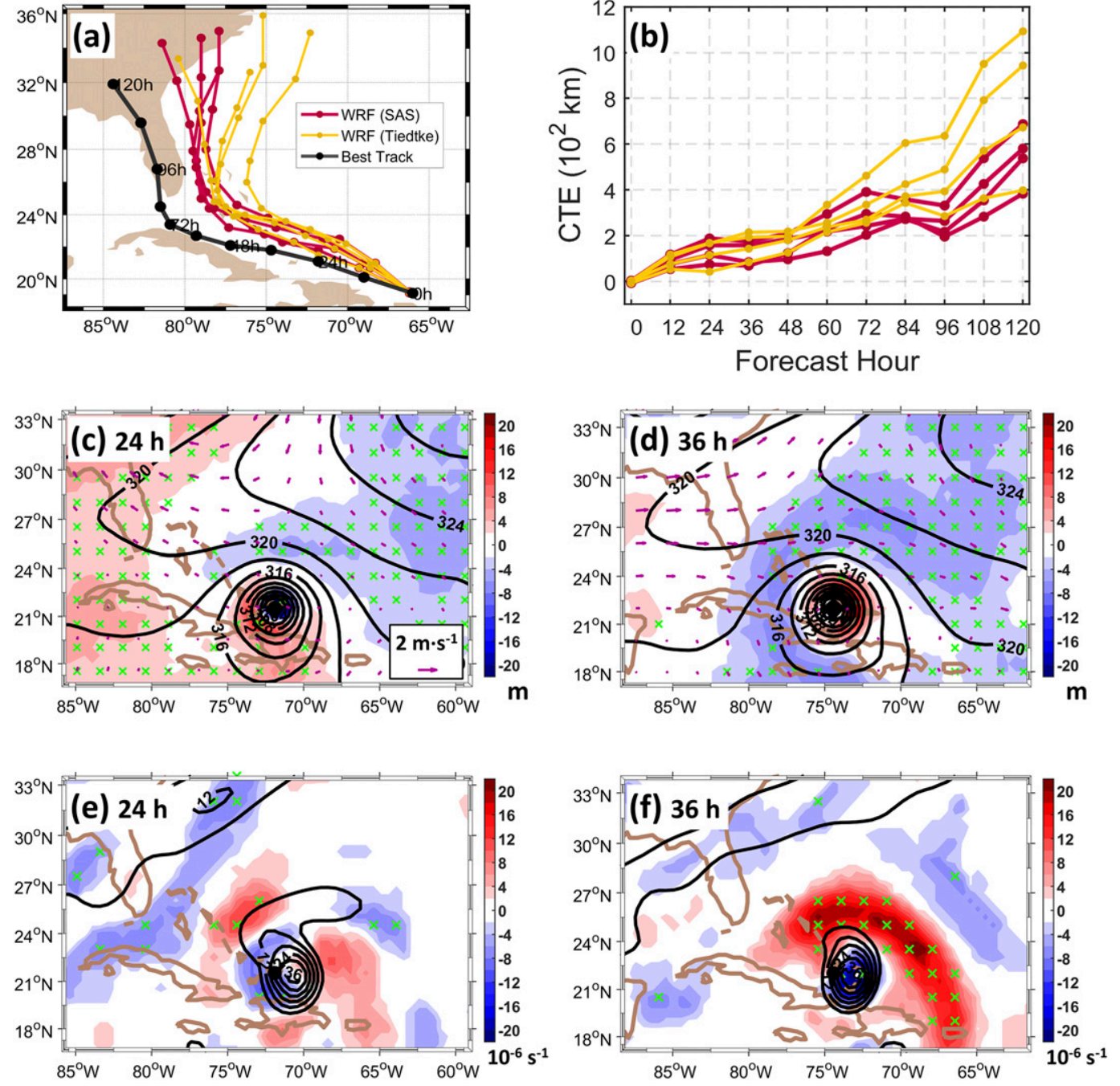

FIG. 19. Rightmost member (a) tracks and (b) CTEs of 36-km WRF runs using the SAS and Tiedtke schemes. WRF-Tiedtke - WRF-SAS differences (not standardized) in TC-centered 700-hPa geopotential heights (shaded) at (c) 24 and (d) $36 \mathrm{~h}$. Black contours are the 700-hPa geopotential heights (dam) of the WRF-SAS mean and vectors are differences in 850-200-hPa environmental steering flow (after removing the TC circulation). (e),(f) As in (c) and (d), but for differences in 300200-hPa divergence, with divergence $\left(10^{-6} \mathrm{~s}^{-1}\right)$ of the WRF-SAS contoured in black. Regions where all rightmost members of WRF-SAS are larger or smaller than WRF-Tiedtke are marked with green crosses.

investigated for the 2008-16 period. This study focuses on the GEFS forecasts for cases not involving extratropical transition (non ET). The lower and upper quartiles of the distribution of GEFS CTEs are compared, which correspond to the largest 25\% left-of-track errors (L25) and the largest $25 \%$ right-of-track errors (R25), respectively. The best tracks of the L25 and R25 cases do not reveal any inherent differences between the two sets, although perhaps more of the R25 cases are steered by easterlies over the main development region.

Composites reveal that $\sim 30 \%$ of the L25 cases are associated with overpredicted $300-\mathrm{hPa}$ heights located less
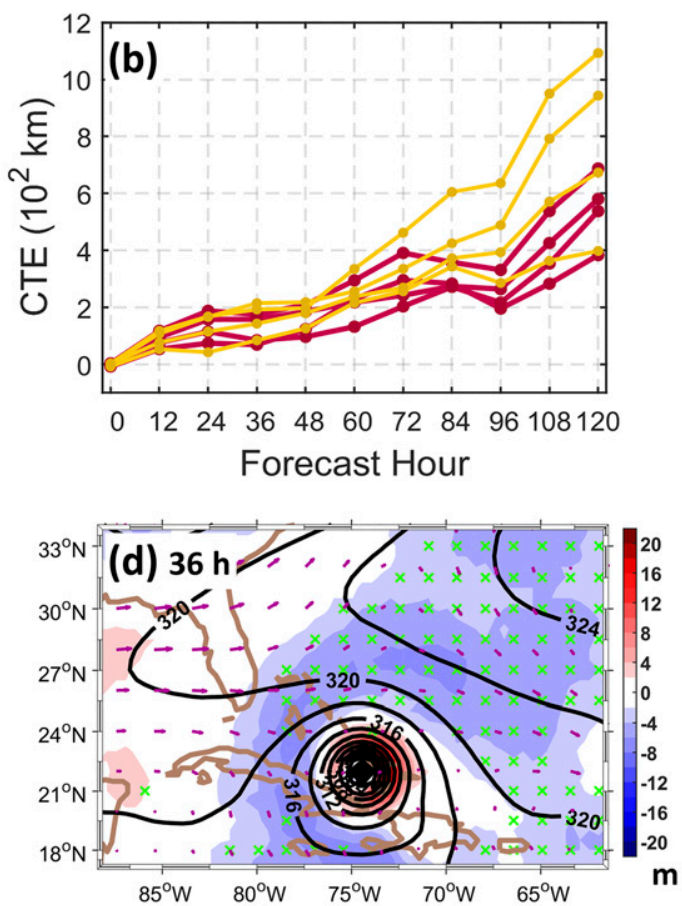

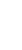


(a)

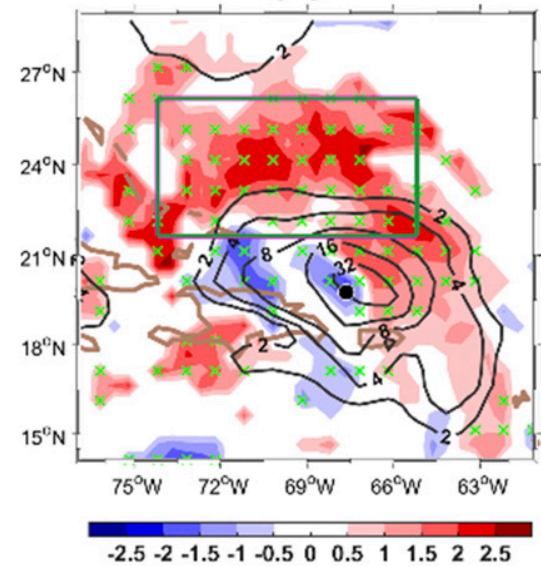

(b)

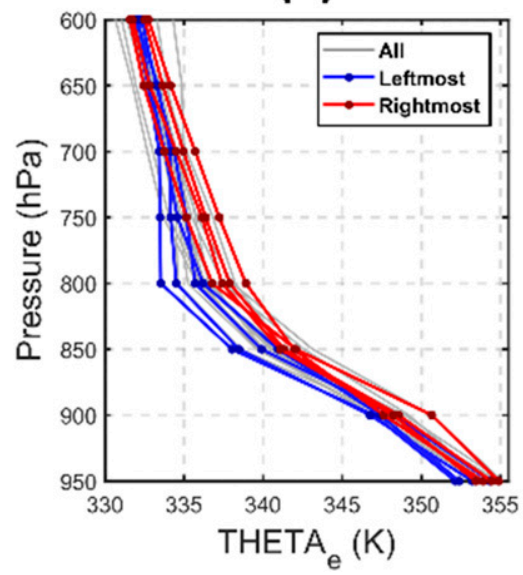

(c)

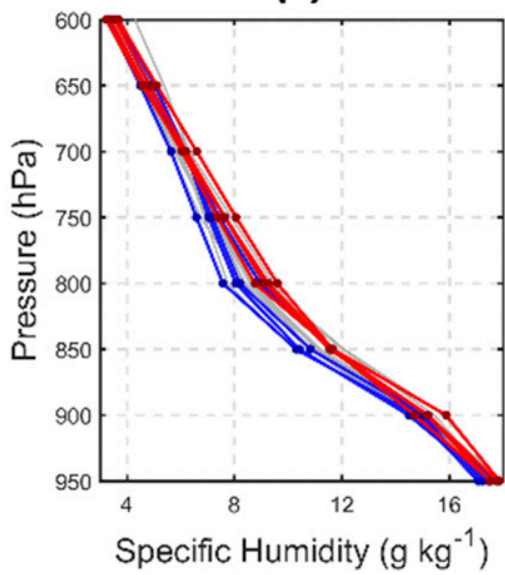

FIG. 20. (a) The 36-km WRF rightmost - leftmost standardized differences in precipitation rate (shaded) at $6 \mathrm{~h}$, with green crosses indicating regions where the difference is statistically significant. The dark-green-outlined box indicates where quantities are area averaged to create vertical profiles. Also shown are vertical profiles of (b) equivalent potential temperature and (c) specific humidity at $0 \mathrm{~h}$.

and Irma (2017). In both cases, the members that move the TC farthest right of track generally have larger integrated kinetic energy than the other members between 12 and $48 \mathrm{~h}$. This difference is consistent with the rightmost members having larger wind fields and hence a broader area of influence on the steering ridge. Height tendency diagnostics confirm that the initially underpredicted $700-\mathrm{hPa}$ heights north of these TCs are exacerbated by excessive divergence occurring mostly above $300 \mathrm{hPa}$. This divergence is associated with overpredicted outer-core convection 300$500 \mathrm{~km}$ northeast of the TC during the first $36 \mathrm{~h}$. The overaggressive convection is also consistent with a broader wind field.

In both cases, the ECMWF ensemble mean track errors are $100-300 \mathrm{~km}$ smaller than the GEFS. The role of the parameterization of convection in this difference is then tested by running WRF with the Tiedtke scheme, which is used by ECMWF. The Tiedtke scheme in WRF generates even more outer-core convection than the SAS scheme. The associated increase in divergence aloft causes more midlevel height falls north of the TC, such that the environmental flow steers the TC farther right of track. For similar reasons, the addition of inner nests down to convection-permitting resolutions $(4 \mathrm{~km})$ also slightly degrade the track forecasts of both cases.

The track errors of these cases are therefore sensitive to the choice of convective scheme, but the ECMWF's usage of the Tiedtke scheme alone may not explain why its track forecasts are better than the GEFS. There may also be a dependence on initial condition errors. The ECMWF appears to better initialize the subtropical ridge and the near-TC environment. For the latter, the ECMWF has less initial low-level moisture and instability, which results in less overaggressive outer-core convection and upper-level divergence weakening the steering ridge. Thus, improvement of the GEFS's forecasts for similar cases may be achieved through better data assimilation of near-TC moisture, stability, and height fields.

The overprediction of the TC's size may also correspond to a stronger beta-drift (Chan and Gray 1982; Holland 1983; Chan and Williams 1987). This effect induces local regions of positive and negative vorticity west and east of the TC, respectively, thereby causing a northward deflection. However, it is difficult to separate the height and vorticity anomalies induced by the beta effect versus those from the dynamical response in the ridge north of the TC.

Future work will run WRF with data assimilation to nudge the initial moisture field to that of the ERAinterim reanalysis (Dee et al. 2011). Given the importance of the initial moisture in TC convection, a more accurate drier environment should reduce the extent of convection and thereby maintain a stronger ridge that steers the TC less right of track. The impact of initial conditions can be further assessed by initializing WRF with the ECMWF ensemble fields and comparing it with the runs initialized with the GEFS, confirming if the results reproduce the differences seen between the original ECMWF and GEFS. It is also important to note that Ike and Irma interacted with Cuba during the first $72 \mathrm{~h}$ of the forecast. The mountainous terrain of Cuba and other Caribbean Islands may have also affected the distribution of convection around the TCs as they approached. Member TCs that interacted less with land may have developed even more convection as they drifted farther north over water. Thus, the impact of topography will be tested in WRF after replacing the model terrain of the Caribbean Islands with ocean. 

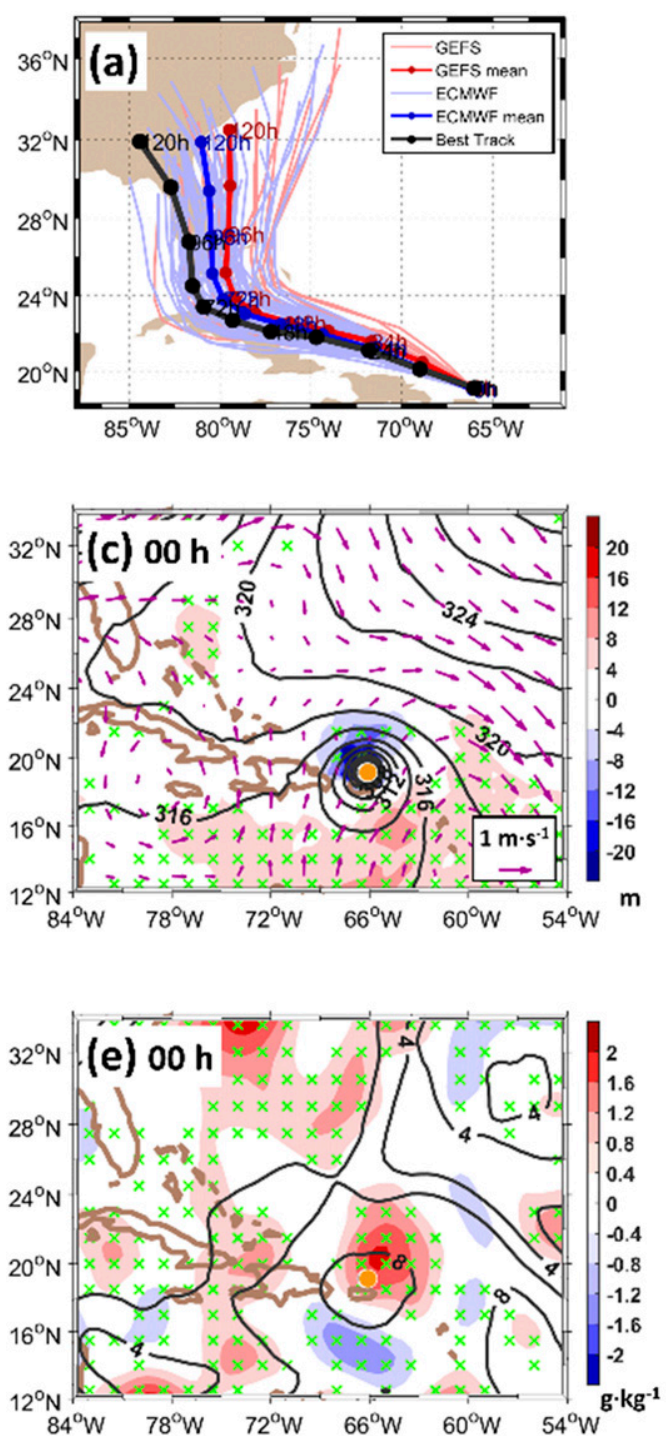
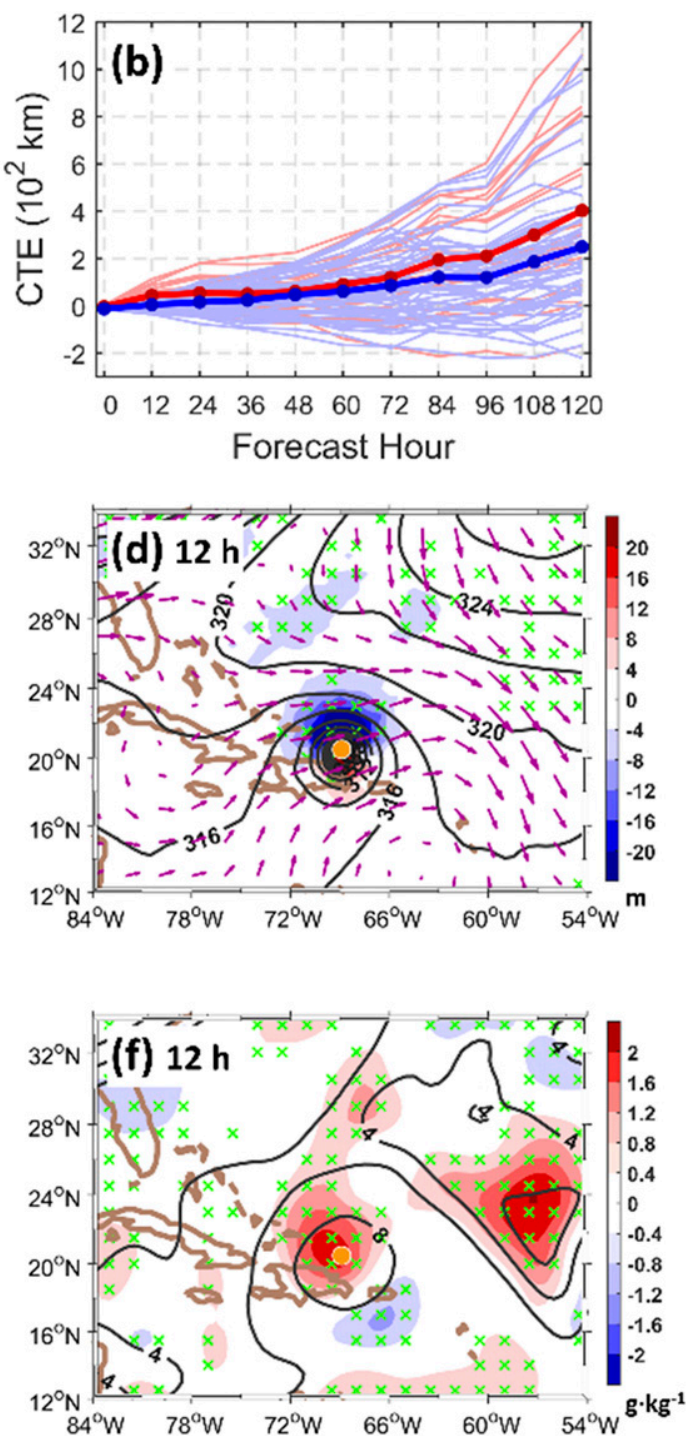

FIG. 21. GEFS and ECMWF (a) forecast tracks and (b) CTEs for Irma, initialized at 0000 UTC 7 Sep 2017. GEFS - ECMWF mean TC-centered differences in 700-hPa height (shaded), 700-hPa heights of the GEFS mean (black contours), and GEFS - ECMWF differences in 850-200-hPa environmental steering flow after removing the TC circulation (vectors) at (c) 0 and (d) $12 \mathrm{~h}$. Green crosses mark regions where the height difference is statistically significant, and orange dots indicate the GEFS mean TC position. (e),(f) As in (c) and (d), but showing differences in 700-hPa specific humidity.

Acknowledgments. This work was funded by the National Science Foundation (Award CMMI-1331269) and NOAA NGPPS (Award NA18NWS4680057). We appreciate the constructive comments of the two anonymous reviewers and Dr. Nicholas Bassill, who helped to improve the paper. We also thank TIGGE for maintaining the archive of ensemble forecast tracks.

\section{REFERENCES}

Aberson, S. D., 2008: Large forecast degradations due to synoptic surveillance during the 2004 and 2005 hurricane seasons. Mon. Wea. Rev., 136, 3138-3150, https://doi.org/10.1175/ 2007MWR2192.1.
Ancell, B. C., and G. J. Hakim, 2007: Comparing adjoint- and ensemble-sensitivity analysis with applications to observation targeting. Mon. Wea. Rev., 135, 4117-4134, https://doi.org/ 10.1175/2007MWR1904.1.

Bougeault, P., and Coauthors, 2010: The THORPEX Interactive Grand Global Ensemble. Bull. Amer. Meteor. Soc., 91, 10591072, https://doi.org/10.1175/2010BAMS2853.1.

Brennan, M. J., D. T. Kleist, K. Howard, and S. J. Majumdar, 2015: The impact of supplemental dropwindsonde data on the structure and intensity of Tropical Storm Karen (2013) in the NCEP global forecast system. Wea. Forecasting, 30, 683-691, https://doi.org/10.1175/WAF-D-15-0002.1.

Buckingham, C., T. Marchok, I. Ginis, L. Rothstein, and D. Rowe, 2010: Short- and medium-range prediction of tropical and 
transitioning cyclone tracks within the NCEP Global Ensemble Forecasting System. Wea. Forecasting, 25, 1736-1754, https:// doi.org/10.1175/2010WAF2222398.1.

Cangialosi, J. P., 2018: National Hurricane Center forecast verification report: 2017 hurricane season. NOAA/National Hurricane Center Rep., 73 pp., https://www.nhc.noaa.gov/verification/ pdfs/Verification_2017.pdf.

Carr, L. E., III, and R. L. Elsberry, 2000: Dynamical tropical cyclone track forecast errors. Part I: Tropical region error sources. Wea. Forecasting, 15, 641-661, https://doi.org/10.1175/ 1520-0434(2000)015<0641:DTCTFE > 2.0.CO;2.

Chan, J. C. L., and W. M. Gray, 1982: Tropical cyclone movement and surrounding flow relationships. Mon. Wea. Rev., 110, 1354-1374, https://doi.org/10.1175/1520-0493(1982)110<1354: TCMASF $>2.0 . \mathrm{CO} ; 2$.

_ _ and R. T. Williams, 1987: Analytical and numerical studies of the beta-effect in tropical cyclone motion. Part I: Zero mean flow. J. Atmos. Sci., 44, 1257-1265, https://doi.org/10.1175/ 1520-0469(1987)044<1257:AANSOT>2.0.CO;2.

Colby, F. P., Jr., 2015: Global ensemble forecast tracks for Tropical Storm Debby. Wea. Forecasting, 30, 668-682, https://doi.org/ 10.1175/WAF-D-14-00083.1.

Dee, D., and Coauthors, 2011: The ERA-Interim reanalysis: Configuration and performance of the data assimilation system. Quart. J. Roy. Meteor. Soc., 137, 553-597, https://doi.org/ 10.1002/qj.828.

Ek, M. B., K. E. Mitchell, Y. Lin, E. Rogers, P. Grunmann, V. Koren, G. Gayno, and J. D. Tarpley, 2003: Implementation of Noah land surface model advances in the National Centers for Environmental Prediction operational mesoscale Eta model. J. Geophys. Res., 108, 8851, https://doi.org/10.1029/2002JD003296.

Galarneau, T. J., Jr., and C. A. Davis, 2013: Diagnosing forecast errors in tropical cyclone motion. Mon. Wea. Rev., 141, 405430, https://doi.org/10.1175/MWR-D-12-00071.1.

Han, J., and H.-L. Pan, 2011: Revision of convection and vertical diffusion schemes in the NCEP global forecast system. Wea. Forecasting, 26, 520-533, https://doi.org/10.1175/WAF-D-10-05038.1.

Holland, G. J., 1983: Tropical cyclone motion: Environmental interaction plus a beta effect. J. Atmos. Sci., 40, 328-342, https:// doi.org/10.1175/1520-0469(1983)040<0328:TCMEIP>2.0.CO;2.

Hong, S. Y., J. Dudhia, and S. H. Chen, 2004: A revised approach to ice microphysical processes for the bulk parameterization of clouds and precipitation. Mon. Wea. Rev., 132, 103-120, https://doi.org/10.1175/1520-0493(2004) 132<0103:ARATIM>2.0.CO;2.

—, Y. Noh, and J. Dudhia, 2006: A new vertical diffusion package with an explicit treatment of entrainment processes. Mon. Wea. Rev., 134, 2318-2341, https://doi.org/10.1175/MWR3199.1.

Kain, J. S., and J. M. Fritsch, 1990: A one-dimensional entraining detraining plume model and its application in convective parameterization. J. Atmos. Sci., 47, 2784-2802, https://doi.org/ 10.1175/1520-0469(1990)047<2784:AODEPM >2.0.CO;2.

Kehoe, R. M., M. A. Boothe, and R. L. Elsberry, 2007: Dynamical tropical cyclone 96- and 120-h track forecast errors in the western North Pacific. Wea. Forecasting, 22, 520-538, https:// doi.org/10.1175/WAF1002.1.

Landsea, C. W., and J. P. Cangialosi, 2018: Have we reached the limits of predictability for tropical cyclone track forecasting? Bull. Amer. Meteor. Soc., 99, 2237-2243, https://doi.org/10.1175/ BAMS-D-17-0136.1.

Leonardo, N. M., and B. A. Colle, 2017: Verification of multimodel ensemble forecasts of North Atlantic tropical cyclones. Wea. Forecasting, 32, 2083-2101, https://doi.org/10.1175/WAF-D17-0058.1.
_ and - 2020: An investigation of large along-track errors in extratropical transitioning North Atlantic tropical cyclone in the ECMWF ensemble. Mon. Wea. Rev., 148, 457-476, https:// doi.org/10.1175/MWR-D-19-0044.1.

Melhauser, C., F. Zhang, Y. Weng, Y. Jin, H. Jin, and Q. Zhao, 2017: A multiple-model convection-permitting ensemble examination of the probabilistic prediction of tropical cyclones: Hurricanes Sandy (2012) and Edouard (2014). Wea. Forecasting, 32, 665-688, https://doi.org/10.1175/WAF-D-16-0082.1.

Pan, H.-L., and W.-S. Wu, 1995: Implementing a mass flux convection parameterization package for the NMC medium-range forecast model. NOAA NWS National Meteorological Center Office Note 409, 43 pp., https://repository.library.noaa.gov/ view/noaa/11429.

Peng, X., J. Fei, X. Huang, and X. Cheng, 2017: Evaluation and error analysis of official forecasts of tropical cyclones during 200514 over the western North Pacific. Part I: Storm tracks. Wea. Forecasting, 32, 689-712, https://doi.org/10.1175/WAF-D-16-0043.1.

Powell, M. D., and T. A. Reinhold, 2007: Tropical cyclone destructive potential by integrated kinetic energy. Bull. Amer. Meteor. Soc., 88, 513-526, https://doi.org/10.1175/BAMS-88-4-513.

Rappaport, E. N., and Coauthors, 2009: Advances and challenges at the National hurricane center. Wea. Forecasting, 24, 395419, https://doi.org/10.1175/2008WAF2222128.1.

Skamarock, W. C., and Coauthors, 2008: A description of the Advanced Research WRF version 3. NCAR Tech. Note NCAR/TN-475+STR, 113 pp., https://doi.org/10.5065/D68S4MVH.

Steenburgh, W. J., and J. R. Holton, 1993: On the interpretation of geopotential height tendency equation. Mon. Wea. Rev., 121, 2642-2645, https://doi.org/10.1175/1520-0493(1993)121<2642: OTIOGH $>2.0 . \mathrm{CO} ; 2$.

Sun, Y., Z. Zhong, and W. Lu, 2015: Sensitivity of tropical cyclone feedback on the intensity of the western Pacific subtropical high to microphysics schemes. J. Atmos. Sci., 72, 1346-1368, https://doi.org/10.1175/JAS-D-14-0051.1.

Taraphdar, S., P. Mukhopadhyay, L. R. Leung, F. Zhang, S. Abhilash, and B. N. Goswami, 2014: The role of moist processes in the intrinsic predictability of Indian Ocean cyclones. J. Geophys. Res. Atmos., 119, 8032-8048, https://doi.org/10.1002/ 2013JD021265.

Torn, R. D., and C. A. Davis, 2012: The influence of shallow convection on tropical cyclone track forecasts. Mon. Wea. Rev., 140, 2188-2197, https://doi.org/10.1175/MWR-D-11-00246.1.

, J. S. Whitaker, P. Pegion, T. M. Hamill, and G. J. Hakim, 2015: Diagnosis of the source of GFS medium-range track errors in Hurricane Sandy (2012). Mon. Wea. Rev., 143, 132152, https://doi.org/10.1175/MWR-D-14-00086.1.

— T. J. Elless, P. P. Papin, and C. A. Davis, 2018: Tropical cyclone track sensitivity in deformation steering flow. Mon. Wea. Rev., 146, 3183-3201, https://doi.org/10.1175/MWR-D-18-0153.1.

Wang, Y. X., Y. Sun, Q. F. Liao, Z. Zhong, Y. J. Hu, and K. F. Liu, 2017: Impact of initial storm intensity and size on the simulation of tropical cyclone track and western Pacific subtropical high extent. J. Meteor. Res., 31, 946-954, https://doi.org/10.1007/s13351-017-7024-3.

Zhang, C., Y. Wang, and K. Hamilton, 2011: Improved representation of boundary layer clouds over the Southeast Pacific in WRF-ARW using a modified Tiedtke cumulus parameterization scheme. Mon. Wea. Rev., 139, 3489-3513, https:// doi.org/10.1175/MWR-D-10-05091.1.

Zwiers, F. W., 1990: The effect of serial correlation on statistical inferences made with resampling procedures. J. Climate, $\mathbf{3}$, 1452-1461, https://doi.org/10.1175/1520-0442(1990)003<1452: TEOSCO $>2.0 . \mathrm{CO} ; 2$. 